\title{
Spread of TEM, VIM, SHV, and CTX-M $\beta$-Lactamases in Imipenem-Resistant Gram-Negative Bacilli Isolated from Egyptian Hospitals
}

\author{
El sayed Hamdy Mohammed, ${ }^{1}$ Ahmed Elsadek Fakhr, ${ }^{2}$ Hanan Mohammed El sayed, ${ }^{2}$ \\ Said abd Elmohsen Al Johery, ${ }^{2}$ and Wesam Abdel Ghani Hassanein ${ }^{1}$ \\ ${ }^{1}$ Department of Botany, Faculty of Science, Zagazig University, Zagazig 44511, Egypt \\ ${ }^{2}$ Department of Medical Microbiology \& Immunology, Faculty of Medicine, Zagazig University, Zagazig 44511, Egypt
}

Correspondence should be addressed to El sayed Hamdy Mohammed; anas.hamdy25@yahoo.com

Received 26 August 2015; Revised 9 December 2015; Accepted 14 December 2015

Academic Editor: Giuseppe Comi

Copyright (C) $2016 \mathrm{El}$ sayed Hamdy Mohammed et al. This is an open access article distributed under the Creative Commons Attribution License, which permits unrestricted use, distribution, and reproduction in any medium, provided the original work is properly cited.

\begin{abstract}
Carbapenem-resistant Gram-negative bacilli resulting from $\beta$-lactamases have been reported to be an important cause of nosocomial infections and are a critical therapeutic problem worldwide. This study aimed to describe the prevalence of imipenemresistant Gram-negative bacilli isolates and detection of $b l a_{\mathrm{VIM}}, b l a_{\mathrm{TEM}}, b l a_{\mathrm{SHV}}, b l a_{\mathrm{CTX}-\mathrm{M}-1}$, and $b l a_{\mathrm{CTX}-\mathrm{M}-9}$ genes in these clinical isolates in Egyptian hospitals. The isolates were collected from various clinical samples, identified by conventional methods and confirmed by API 20E. Antibiotic susceptibility testing was determined by Kirby-Bauer technique and interpreted according to CLSI. Production of $b l a_{\mathrm{VIM}}, b l a_{\mathrm{TEM}}, b l a_{\mathrm{SHV}}$, and $b l a_{\mathrm{CTX}-\mathrm{M}}$ genes was done by polymerase chain reaction (PCR). Direct sequencing from PCR products was subsequently carried out to identify and confirm these $\beta$-lactamases genes. Out of 65 isolates, (46.1\%) Escherichia coli, (26.2\%) Klebsiella pneumoniae, and (10.7\%) Pseudomonas aeruginosa were identified as the commonest Gramnegative bacilli. $33(50.8 \%)$ were imipenem-resistant isolates. 22 isolates $(66.7 \%)$ carried $b l a_{\mathrm{VIM}}, 24(72.7 \%)$ had $b l a_{\mathrm{TEM}}$, and 5(15\%) showed $b l a_{\mathrm{SHV}}$, while $12(36 \%), 6(18.2 \%)$, and $0(0.00 \%)$ harbored $b l a_{\mathrm{CTX}-\mathrm{M}-1}, b l a_{\mathrm{CTX}-\mathrm{M}-9}$, and $b l a_{\mathrm{CTX}-\mathrm{M}-8 / 25}$, respectively. There is a high occurrence of $\beta$-lactamase genes in clinical isolates and sequence analysis of amplified genes showed differences between multiple SNPs (single nucleotide polymorphism) sites in the same gene among local isolates in relation to published sequences.
\end{abstract}

\section{Introduction}

Gram-negative bacilli are a heterogeneous group of Gramnegative bacteria that are common commensals, infectious agents and also sometimes referred to as "nightmare bacteria" [1]. Hospital acquired infections due to Gram-negative bacilli are a leading cause of morbidity and mortality worldwide [2].

Carbapenem, a member of the $\beta$-lactam family, has a broad spectrum of activity and is stable to most $\beta$-lactamases. These properties make carbapenem an important therapeutic option for treating serious infections involving resistant strains of Enterobacteriaceae, anaerobes, Pseudomonas aeruginosa, and Acinetobacter spp. [3], although carbapenems, including imipenem and meropenem, are often used as "antibiotics of last resort" when patients with infections become severely ill or are suspected of harboring resistant bacteria [4]. However, carbapenem-resistant Gram-negative bacilli isolates were increasingly reported worldwide [5].

This resistance may be attributed to presence of metallo$\beta$-lactamase in bacteria such as IMP (Imipenemase), VIM (Verona-Integron metallo- $\beta$-lactamase) [6], and extended spectrum $\beta$-lactamases (ESBLs) such as SHV, TEM, and CTX-M [7].

For establishment of appropriate antimicrobial therapy and control of the spread of drug resistant Gram-negative bacilli, the PCR-based detection methods of resistant genes show the bioinformatics analysis of their molecular diversity and evolution becoming increasingly important [8].

This work aimed to study distribution of imipenemresistant Gram-negative isolates and shed focused light on 
TABLE 1: Primer name, primer sequences, and expected amplicon size of amplified DNA products.

\begin{tabular}{|c|c|c|c|c|}
\hline PCR name & $\beta$-lactamase targeted & Primer name & Sequence $\left(5^{\prime}-3^{\prime}\right)$ & Amplicon size (bp) \\
\hline \multirow{2}{*}{ VIM } & \multirow{2}{*}{$\begin{array}{l}\text { VIM variants including VIM-1 and } \\
\text { VIM-2 }\end{array}$} & VIM-for & GATGGTGTTTGGTCGCATA & \multirow{2}{*}{390} \\
\hline & & VIM-rev & CGAATGCGCAGCACCAG & \\
\hline \multirow{2}{*}{ TEM } & \multirow{2}{*}{$\begin{array}{l}\text { TEM variants including TEM-1 and } \\
\text { TEM-2 }\end{array}$} & TSO-T-for & CATTTCCGTGTCGCCCTTATTC & \multirow{2}{*}{800} \\
\hline & & TSO-T-rev & CGTTCATCCATAGTTGCCTGAC & \\
\hline \multirow{2}{*}{ SHV } & \multirow{2}{*}{ SHV variants including SHV-1 } & TSO-S-for & AGCCGCTTGAGCAAATTAAAC & \multirow{2}{*}{713} \\
\hline & & TSO-S-rev & ATCCCGCAGATAAATCACCAC & \\
\hline \multirow{2}{*}{$\begin{array}{l}\text { CTX-M } \\
\text { group } 1\end{array}$} & \multirow{2}{*}{$\begin{array}{l}\text { Variants of CTX-M group } 1 \text { including } \\
\text { CTX-M-1, CTX-M-3, and CTX-M-15 }\end{array}$} & CTXMGp 1-for & TTAGGAARTGTGCCGCTGYA $^{\mathrm{b}}$ & \multirow{2}{*}{688} \\
\hline & & CTXMGp $1.2 \mathrm{rev}$ & CGATATCGTTGGTGGTRCCAT & \\
\hline \multirow{2}{*}{$\begin{array}{l}\text { CTX-M } \\
\text { group } 9\end{array}$} & \multirow{2}{*}{$\begin{array}{l}\text { Variants of CTX-M-9 including } \\
\text { CTX-M-9 and CTX-M-14 }\end{array}$} & CTX-9-F & TCAAGCCTGCCGATCTGGT & \multirow{2}{*}{561} \\
\hline & & CTX-9-R & TGATTCTCGCCGCTGAAG & \\
\hline \multirow{2}{*}{$\begin{array}{l}\text { CTX-M } \\
\text { group } 8 / 25\end{array}$} & \multirow{2}{*}{$\begin{array}{l}\text { CTX-M-8, CTX-M-25, CTX-M-26, and } \\
\text { CTX-M-39 to CTX-M-41 }\end{array}$} & CTX-8/25-F & AACRCRCAGACGCTCTAC ${ }^{\mathrm{b}}$ & \multirow{2}{*}{326} \\
\hline & & CTX-8/25-R & TCGAGCCGGAASGTGTYAT ${ }^{\mathrm{b}}$ & \\
\hline
\end{tabular}

${ }^{\mathrm{b}} \mathrm{Y}=\mathrm{T}$ or $\mathrm{C} ; \mathrm{R}=\mathrm{A}$ or $\mathrm{G} ; \mathrm{S}=\mathrm{G}$ or $\mathrm{C}$.

some genes encoding beta-lactamase enzymes responsible for such resistance in Zagazig University Hospitals in Egypt.

\section{Material and Methods}

2.1. Bacterial Isolates. Clinical isolates of Gram-negative bacilli including Escherichia coli $(n=30)$, Klebsiella pneumoniae $(n=17)$, Pseudomonas aeruginosa $(n=7)$, Proteus mirabilis $(n=2)$, Citrobacter freundii $(n=1)$, Acinetobacter baumanii $(n=3)$, and Enterobacter cloacae $(n=4)$ were collected from blood, urine, pus, and sputum specimens from hospitalized patients in Zagazig University Hospitals in Egypt from January 2013 to March 2014. These clinical samples were processed by plating on blood agar and MacConkey agar [9]. A growth temperature of $44^{\circ} \mathrm{C}$ was used sometimes to confirm the identity of these isolates and the identified strains were stored in glycerol $(20 \% \mathrm{~V} / \mathrm{V})$ at $70^{\circ} \mathrm{C}$ and subcultured several times to be viable. All isolates were identified by standard biochemical tests [10] and confirmed by API 20E (BioMérieux, Marcy l'Étoile, France).

2.2. Antibiotic Susceptibility Testing. The susceptibility testing of studied isolates was performed by disc diffusion method (modified Kirby-Bauer method) using Muller-Hinton agar (Becton Dickinson, MA, USA) and interpreted according to the Clinical Laboratory Standard Institute (CLSI) guidelines [11]. The antibiotic disks used imipenem (IPM, $10 \mu \mathrm{g}$ ), amikacin (AK, $30 \mu \mathrm{g}$ ), ciprofloxacin (CIP, $5 \mu \mathrm{g}$ ), piperacillin (PRL, $100 \mu \mathrm{g})$, cefoperazone/sulbactam (CES, $10+5 \mu \mathrm{g}$ ), cefoxitin (FOX, $30 \mu \mathrm{g}$ ), and cefotaxime (CTX, $30 \mu \mathrm{g}$ ) which were placed $15 \mathrm{~mm}$ away from the central disc and the plates were incubated for about $18-24$ hrs at $37^{\circ} \mathrm{C}$.

2.3. Molecular Detection of $\beta$-Lactamase Genes by PCR. For detection of $\beta$-lactamase genes responsible for imipenemresistance, rapid genomic DNA was prepared from about five colonies heated in $100 \mathrm{~mL}$ distilled water $\left(95^{\circ} \mathrm{C}\right.$ for $10 \mathrm{~min}$ ) followed by a centrifugation step of cell suspension at
$12.000 \mathrm{rpm}$ for $5 \mathrm{~min}$; then supernatant was taken as a source of template DNA. PCR amplification was carried out by using DNA thermal cycler (Biometra, Singapore) using a specific primer for $b l a_{\mathrm{VIM}}, b l a_{\mathrm{TEM}}, b l a_{\mathrm{SHV}}, b l a_{\mathrm{CTX}-\mathrm{M}-1}, b l a_{\mathrm{CTX}-\mathrm{M}-9}$, and $b l a_{\mathrm{CTX}-\mathrm{M}-8 / 25}$ (Table 1 ), in a $50 \mu \mathrm{L}$ volume containing $10 \mathrm{x}$ PCR buffer, $2 \mathrm{mM}$ deoxynucleoside triphosphates, $3.4 \mathrm{pmol}$ of each primer, $2.5 \mathrm{mM} \mathrm{MgCl}_{2}, 1 \mathrm{U}$ Taq DNA polymerase, and $1 \mu \mathrm{L}$ of genomic DNA [12]. Amplification was carried out as follows: initial denaturation at $94^{\circ} \mathrm{C}$ for 10 minutes, followed by 40 cycles of DNA denaturation at $94^{\circ} \mathrm{C}$ for 40 seconds, primer annealing at $60^{\circ} \mathrm{C}$ for 40 seconds and primer extension at $72^{\circ} \mathrm{C}$ for 1 minute, and a final elongation step at $72^{\circ} \mathrm{C}$ for 7 minutes. The annealing temperature was optimal at $55^{\circ} \mathrm{C}$ instead of $60^{\circ} \mathrm{C}$ for amplification of $b l a_{\mathrm{VIM}}$. Amplicons were then visualized after running in $2 \%$ agarose gel at $100 \mathrm{~V}$ for 30 mins. A 50-1000 bp DNA ladder (USA) was used as a size marker. Finally, PCR products were purified with innuPREP PCRpure kit (Analytik Jena, Germany) and subjected to direct sequencing via GATC Company by use of ABI 3730xl DNA sequencer.

2.4. Bioinformatics and Sequences Analysis. The obtained chromatogram sequencing files were inspected and corrected using the software application Chromas 2.3 (Technelysium, Helensvale, Australia) and JalView (2.8).

The sequences obtained from our samples were aligned with GenBank sequences. The phylogenetic tree for each sequence was obtained by performing neighbor-joining analysis of the alignment of sequences with reference strains (accession numbers/country of origin) that were retrieved from GenBank. The studied strains were marked by the sign [घ]. Meanwhile, the reference sequences were marked by the $\operatorname{sign}[\mathbf{\Delta}]$.

The BLAST and FASTA programs of the National Center for Biotechnology Information (http://blast.ncbi.nlm.nih .gov/Blast.cgi) were used to search databases for similar nucleotide sequences [13]. Multiple sequence alignments of the nucleic acid were carried out using the ClustalW program. The statistical analysis was performed using SPSS version 


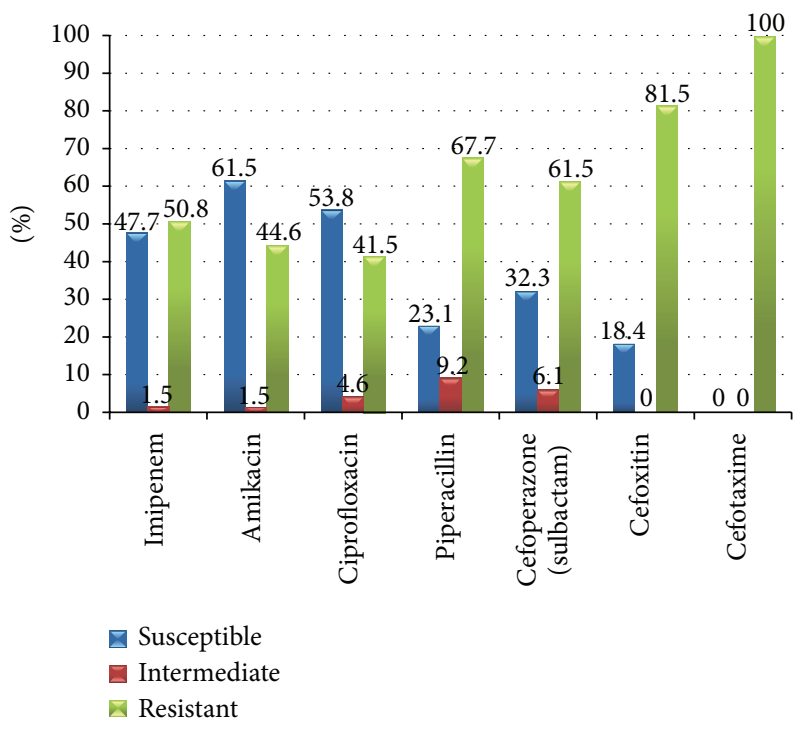

FIgURE 1: Antimicrobial susceptibility patterns of all 65 Gramnegative bacilli isolates.

20.0, $\chi^{2}=$ chi-square test , and $P$ values $<0.05$ were considered significant.

\section{Results}

3.1. Isolation and Identification. The present study was conducted on 65 screened isolates of Gram-negative bacilli, obtained from 108 various clinical samples such as urine, blood, pus, and sputum, where $41(78.8 \%)$ were isolated from urine, 12 (66.6\%) from blood, 14 (48.2\%) from respiratory secretions, and 2 (22.2\%) from pus. Escherichia coli (46.1\%) was the most commonly isolated organism among Gram-negative bacilli, followed by Klebsiella pneumoniae (26.2\%), Pseudomonas aeruginosa (10.7\%), Enterobacter cloacae (6.1\%), Proteus mirabilis (3.07\%), and Acinetobacter baumanii (4.6\%) while Citrobacter freundii and Proteus vulgaris gave $1.5 \%$. The isolation of Gram-negative bacilli isolates was significantly higher in patients with trauma $(P<0.001)$, those hospitalized for more than 7 days $(P<0.001)$, and those with ICU admission $(P<0.001)$ harboring risk factors for acquiring Gram-negative bacilli infection.

3.2. The Antibiotic Susceptibility Testing. It was shown in Figure 1, as observed, that $40(61.5 \%)$ were susceptible to amikacin, $35(53.8 \%)$ were susceptible to ciprofloxacin, $31(47.7 \%)$ were susceptible to imipenem, and $21(32.3 \%)$ were susceptible to cefoperazone/sulbactam. However, all isolates were resistant to cefotaxime (100\%), 53 (81.5\%) of isolates were resistant to cefoxitin, $44(67.7 \%)$ were resistant to piperacillin, $40(61.5 \%)$ were resistant to cefoperazone/sulbactam, 33 (50.8\%) were resistant to imipenem followed by 24 (44.6\%) resistant to amikacin, and 27 (41.5\%) were resistant to ciprofloxacin.

3.3. PCR Assay Results. As shown in Table 6, of 33 imipenemresistant Gram-negative bacillistrains, the results of PCR amplification products of $\beta$-lactamases genes showed that $66.7 \%$ of isolates carried $b l a_{\mathrm{VIM}}$ at $390 \mathrm{bp}$ (Figure 2(a)), $72.7 \%$ had $b l a_{\mathrm{TEM}}$ at $800 \mathrm{bp}$ (Figure 2(b)), 36.0\% harbored $b l a_{\mathrm{CTX}-\mathrm{M}-1}$ at $688 \mathrm{bp}$ (Figure 2(c)), and $15.0 \%$ showed $b l a_{\mathrm{SHV}}$ (Figure 2(d)), while 18.2\% (Figure 2(e)), 0.00\% (Figure 2(f)) harbored $b l a_{\mathrm{CTX}-\mathrm{M}-9}, b l a_{\mathrm{CTX}-\mathrm{M}-8 / 25}$, respectively. Sequencing confirmed presence of these $\beta$-lactamase genes; the GenBank nucleotide sequence accession numbers for the sequences studied are detailed. Aligning of the obtained sequences with those of reference strains in GenBank confirmed the correct identification of $b l a_{\mathrm{VIM}}, b l a_{\mathrm{TEM}}, b l a_{\mathrm{SHV}}$, and $b l a_{\mathrm{CTX}-\mathrm{M}}$ genes by PCR.

\subsection{Sequences Analysis and Polymorphism}

3.4.1. The Analysis of VIM Gene $\left(b l a_{\mathrm{VIM} 1,2}\right)$. The sequence of the purified product of VIM gene $\left(b l a_{\mathrm{VIM} 1,2}\right)$ was compared with homologous GenBank sequences using BLAST program and resulted in significant similarity to many metallo- $\beta$ lactamases genes of different bacterial strains.

(1) VIM Gene $\left(b a_{V I M 1,2}\right)$ in Escherichia coli Strains. The pairwise sequences alignments of resulting VIM gene $\left(b l a_{\mathrm{VIM} 1,2}\right)$ in E. coli strains, isolated from Zagazig University (ZU) Hospitals, in comparison with published VIM gene in $E$. coli strains from GenBank, for example (E. coli KC417377.1), showed single common SNP (single nucleotide polymorphism) sites between the different strains. The SNPs position was indicated in position 382 in the Egyptian strains (Figure 3(a)). The phylogenetic tree of VIM gene sequence in E. coli strains, isolated from Zagazig University Hospitals, and published homologous sequences in GenBank showed different degrees of dis/similarity between the different strains (Figure 3(b)). It was interesting to detect that both strains, the most similar and most dissimilar strains, were from the same country, Greece, indicating biodiversity in the same geographical location.

(2) VIM Gene (bla VIM1,2 $_{2}$ ) in Klebsiella pneumoniae Strains. The VIM gene isolated from K. pneumoniae strains in Zagazig University Hospitals was compared with published VIM gene in K. pneumoniae strains from GenBank (e.g. K. pneumoniae DQ143913.1). The results showed 6 different common SNPs between the different strains. The SNPs positions were indicated in 45, 150, 168, 284, 309, and 363 (Figure 3(c)). The phylogenetic tree of VIM gene sequence in K. pneumoniae strains, isolated from ZU Hospitals, and published homologous sequences in GenBank showed different degrees of dis/similarity between the different strains with many unique sequences in the Egyptian strain (Figure 3(d)).

(3) VIM Gene (bla VIMI,2 $_{2}$ ) in Acinetobacter baumanii Strains. The sequence of purified product of VIM gene $\left(b l a_{\mathrm{VIM} 1,2}\right)$ from Acinetobacter baumanii strain was compared with the GenBank sequence using BLAST program. Interestingly, it was revealed that there was a single strain present in GenBank which is completely different from the studied strains and this is not matching with our study (e.g., Staphylococcus phage StB12, complete genome). The sequence alignment showed 9 


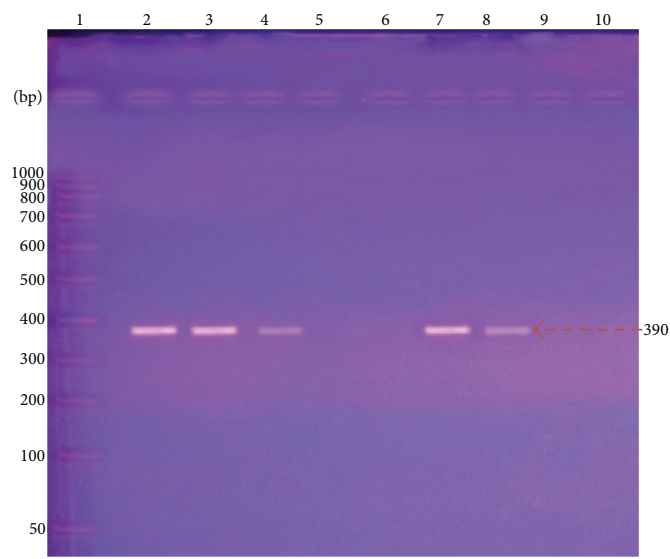

(a)

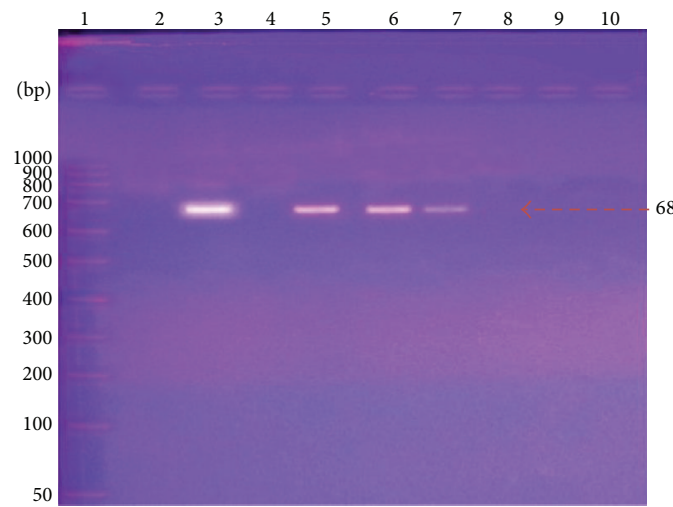

(c)

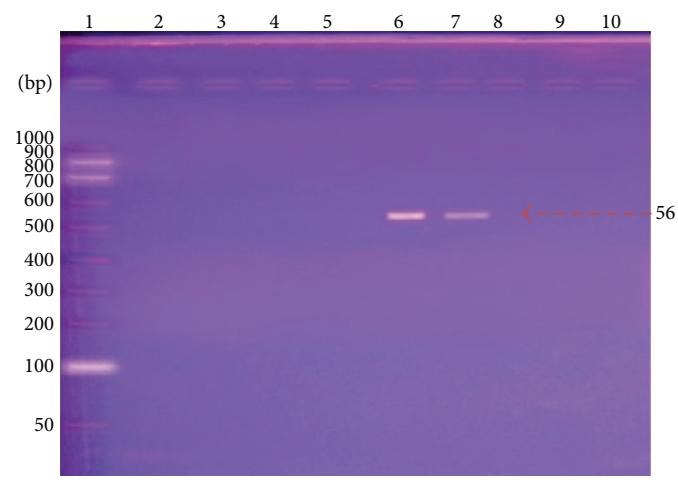

(e)

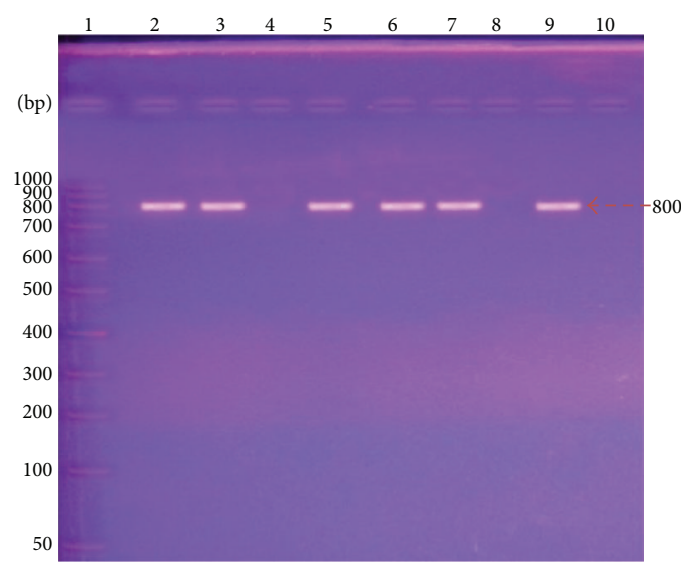

(b)

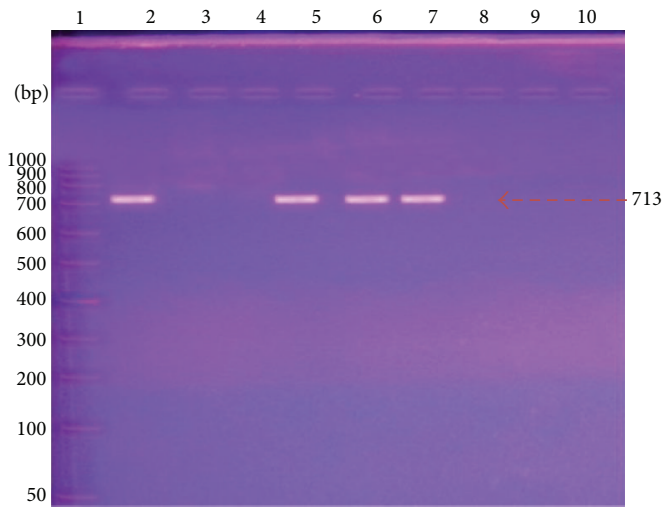

(d)

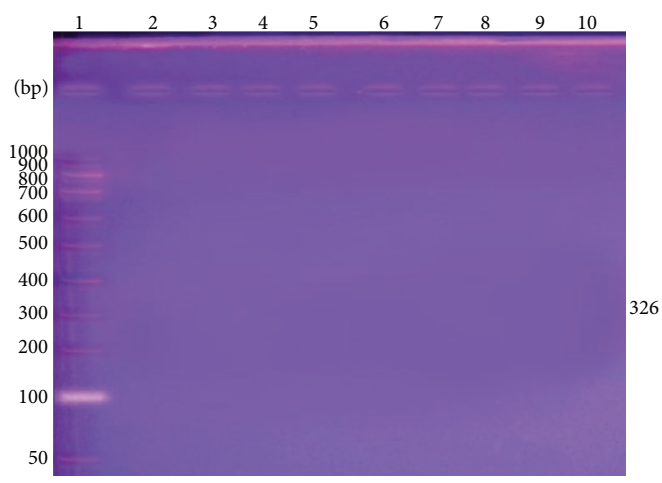

(f)

FIGURE 2: Presence and absence of $\beta$-lactamase genes by PCR amplification in some isolated samples. (a) The existence of VIM amplification fragment (390 bp). (b) The amplification of TEM fragments ( $800 \mathrm{bp})$. (c) The amplification of CTX-M-1 (688 bp). (d) The presence of SHV (713 bp) in some samples. (e) The presence of CTX-M-9 (561 bp). (f) No amplification was shown with CTX-M-8/25 primer at 326 bp.

different common SNPs between the different strains. These positions were indicated in 246, 284, 306, 309, 330, 363, 378, 382, and 383 (Figure 3(e)). The phylogenetic tree of VIM sequence of $A$. baumanii isolated from $\mathrm{ZU}$ Hospitals and published ones in GenBank showed dissimilarity between Egyptian strains and others (Figure 3(f)).

3.4.2. Sequence Analysis of TEM Gene $\left(b l a_{\mathrm{VIM} 1,2}\right)$. Sequences of the purified product of VIM gene $\left(b l a_{\mathrm{VIM} 1,2}\right)$ were compared with homologous counterpart GenBank database using
BLAST program and resulted in significant similarity to many metallo- $\beta$-lactamases genes of different bacterial strains.

(1) TEM Gene $\left(b l a_{T E M 1,2}\right)$ of Escherichia coli. The TEM gene sequences of $E$. coli strains, isolated from ZU Hospitals, were aligned with sequences of published TEM genes in $E$. coli strains from GenBank (e.g., E. coli KM598665.1). The resulting alignments showed 4 different common SNP sites between the different strains. The SNPs positions were indicated commonly in 216, 232, 385, and 433 (Figure 4(a)). Phylogenetic tree was constructed from TEM gene $\left(b l a_{\mathrm{TEM} 1,2}\right)$ 


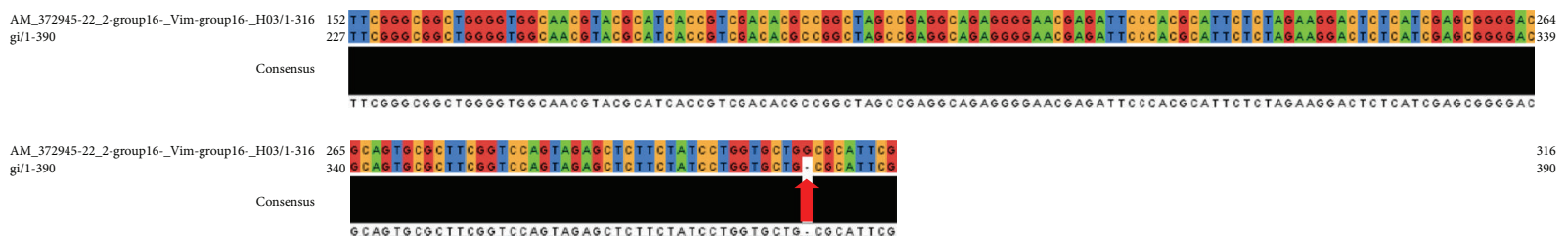

(a)

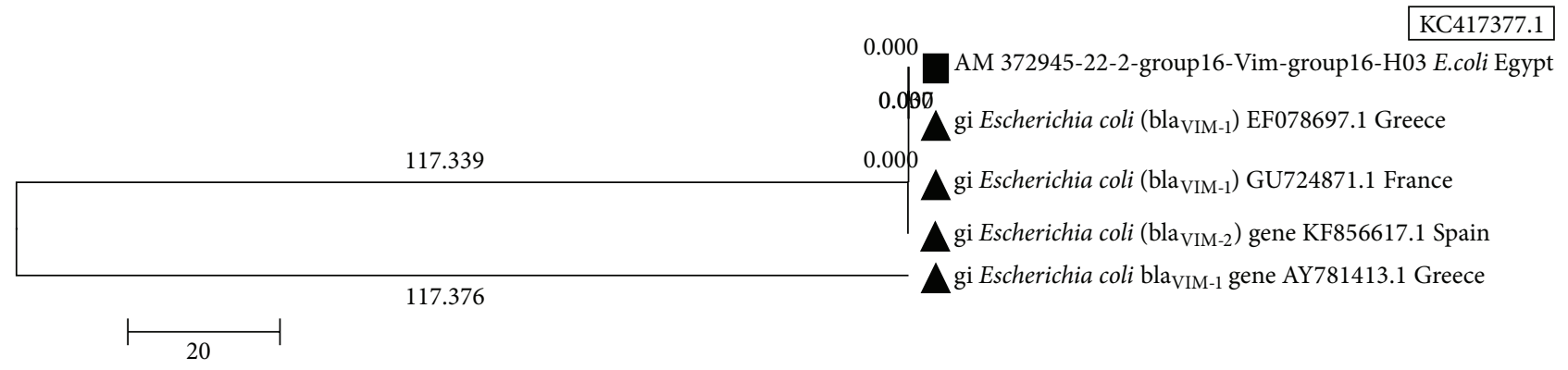

(b)
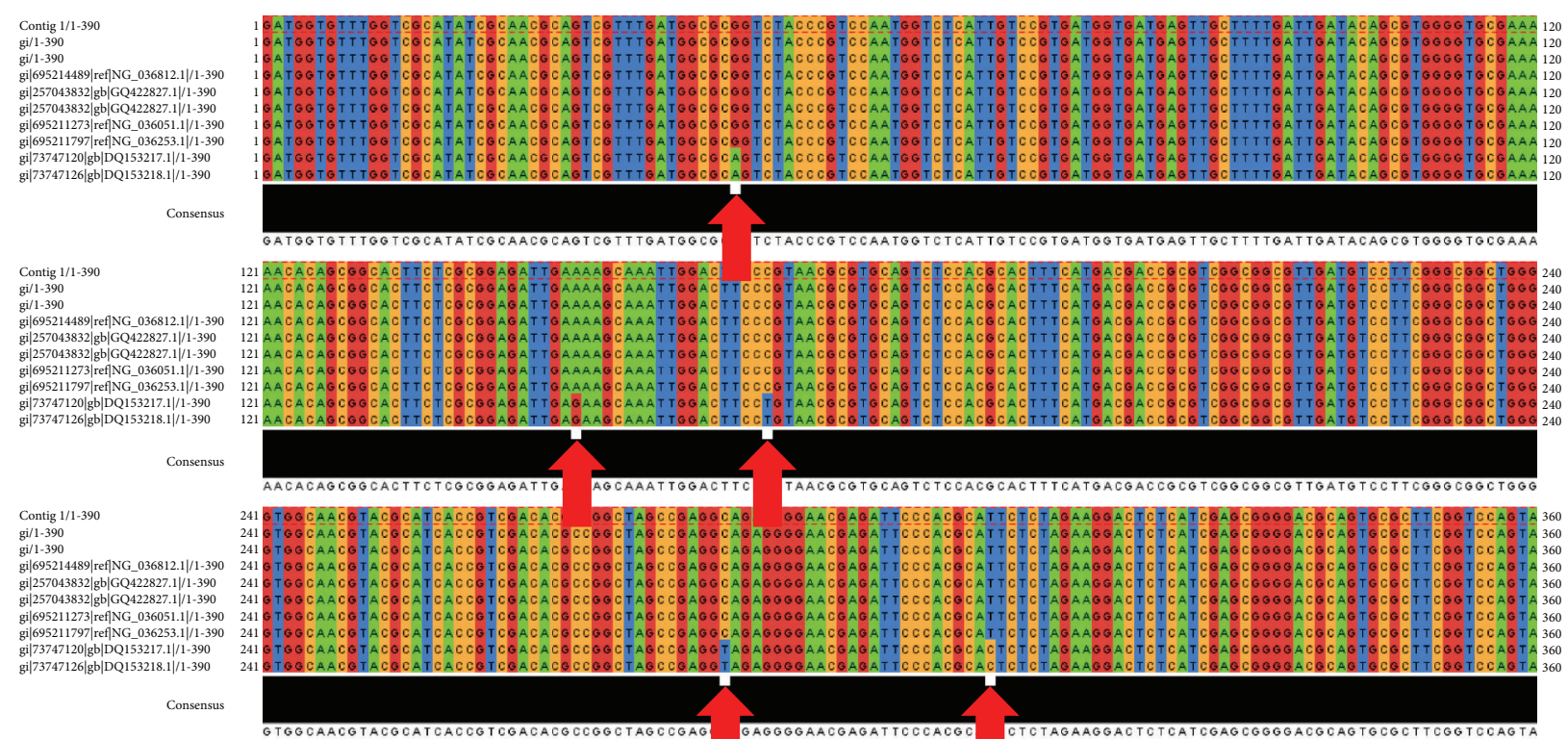

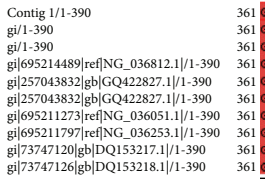

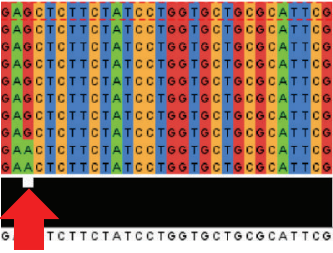

390
390
390
390
390
390
390
390
390
390

(c)

DQ143913.1

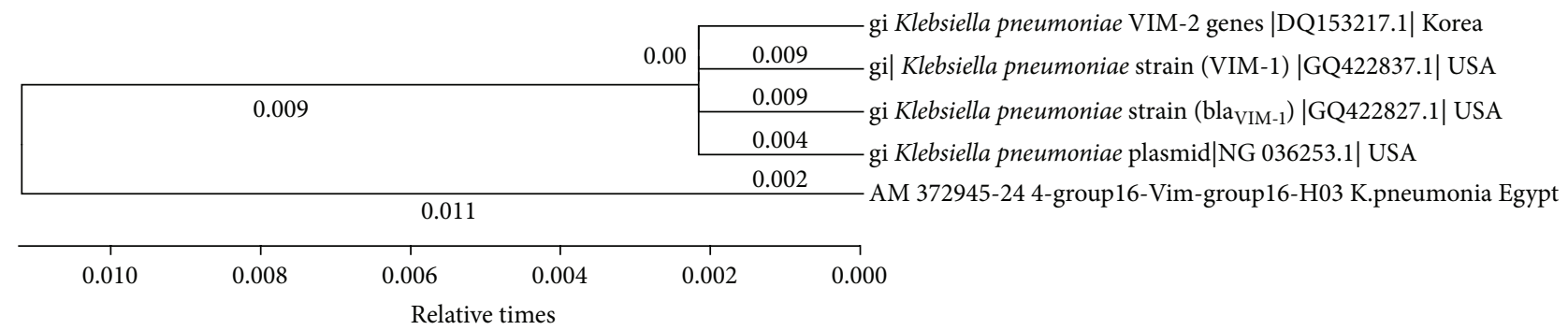

(d)

Figure 3: Continued. 


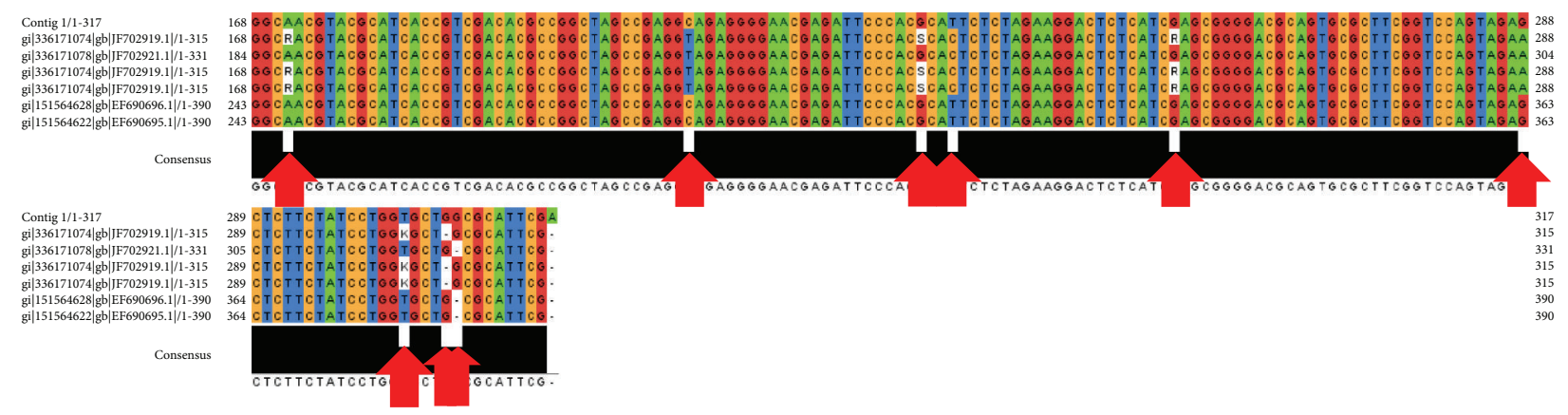

(e)

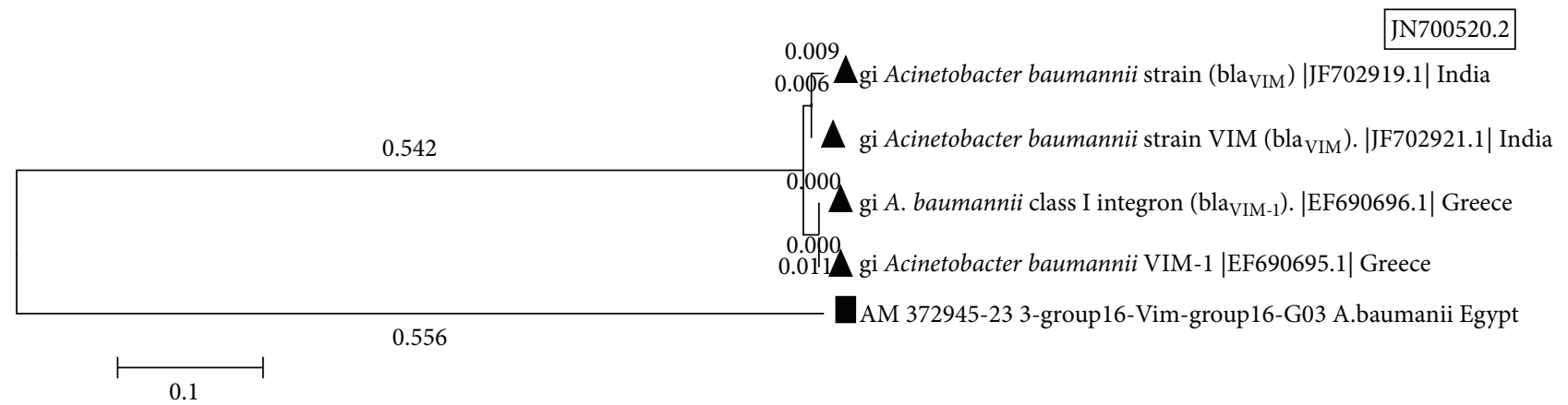

(f)

Figure 3: The multiple sequences alignments and trees of VIM gene in different species. (a) VIM gene in E. coli strains isolated from Zagazig University (ZU) Hospitals in comparison with published VIM gene of E. coli strains from GenBank. (b) A tree of VIM sequence of E. coli isolated from ZU Hospitals and published homologs in GenBank. (c) The multiple sequences alignments of VIM gene in K. pneumoniae strains isolated from ZU Hospitals in comparison with published VIM gene in K. pneumoniae strains from GenBank. (d) Phylogenetic tree of VIM sequence of K. pneumoniae isolated from ZU Hospitals and published sequences in GenBank. (e) The multiple sequences alignments of VIM gene in A. baumanii strains isolated from ZU Hospitals in comparison with published VIM gene in A. baumanii strains from GenBank. (f) Phylogenetic tree of VIM sequence of A. baumanii isolated from ZU Hospitals and published sequences in GenBank.

sequence of Escherichia coli strains isolated from ZU Hospitals and published homologous sequences in GenBank (Figure 4(b)) showing similarity degree between Egyptian and Indian strains.

(2) TEM Gene (bla $\left.a_{T E M 1,2}\right)$ of Klebsiella pneumonia. Multiple sequences alignments of TEM gene in K. pneumoniae strains, isolated from ZU Hospitals, were compared with other published TEM genes in K. pneumoniae strains from GenBank (e.g., K. pneumoniae KF268357.1). (Figure 4(c)) showed 2 different common SNPs between different strains. The SNPs positions were indicated in 174 and 343. A phylogenetic tree of TEM sequence of $K$. pneumoniae isolated from Zagazig University Hospitals and other published ones in GenBank showed the degree of similarity between strains where Egyptian strain was dissimilar to that of Iranian and Indian strains (Figure 4(d)).

3.4.3. The Analysis of SHV Gene (bla $\left.a_{\mathrm{SHV} 1}\right)$ in Klebsiella pneumoniae Strains. The pairwise sequences alignments of resulting SHV gene $\left(b l a_{\mathrm{SHV} 1}\right)$ in $K$. pneumoniae strains, isolated from Zagazig University Hospitals, in comparison with published SHV gene in K. pneumoniae strains from GenBank using BLAST program (e,g., K. pneumoniae AF124984.1) showed five common SNPs between the different strains. The SNPs position was indicated in 454, 563, 631, 635, and 650 in Egyptian strains (Figure 5(a)). The phylogenetic tree of SHV gene in this case showed that Egyptian strain was more similar to France strain (Figure 5(b)).

3.4.4. The Analysis of CTX-M-1 Gene $\left(b l a_{\mathrm{CTX}-\mathrm{M}-1}\right)$. Sequences of the purified product of CTX-M-1 gene $\left(b l a_{\mathrm{CTX}-\mathrm{M}-1}\right)$ were compared with homologous counterpart GenBank database using BLAST program and resulted in significant similarity to many metallo- $\beta$-lactamases genes of different bacterial strains.

(1) CTX-M-1 Gene (bla $\left.a_{C T X-M-1}\right)$ of Escherichia coli Strains. The sequence of the purified product of CTX-M-1 gene from Escherichia coli strains was compared with the GenBank sequence using BLAST program. Interestingly, it was revealed that there were strains present in GenBank which are completely different from the studied strains and this is not matching with our study (e.g., Pseudomonas aeruginosa DNA, AP014646.1). The sequence alignment showed 81 different common SNPs between the different strains. The SNPs positions were indicated in 601, 604 $\rightarrow$ 615, 617 $\rightarrow$ 626, and $628 \rightarrow 688$ (Figure $6(\mathrm{a})$ ). The phylogenetic tree of CTX-M-1 


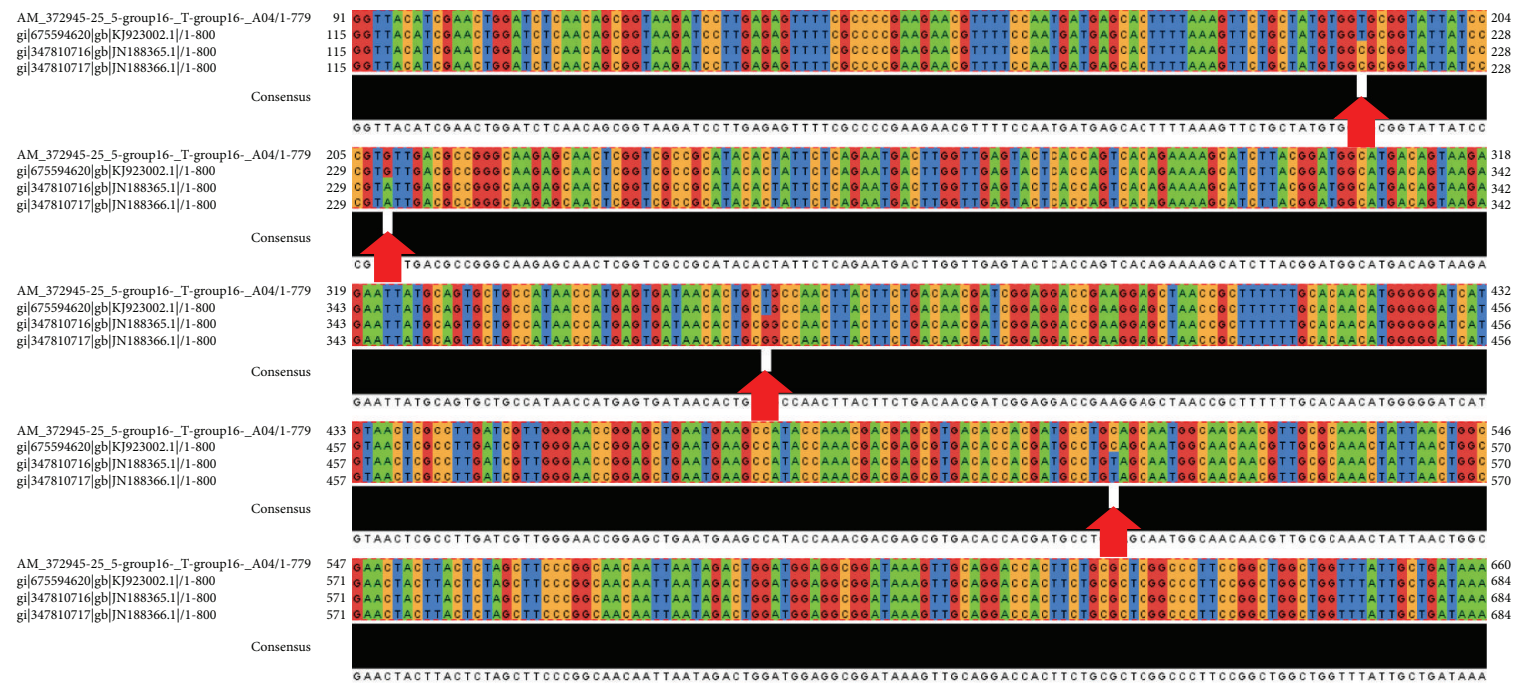

(a)

\begin{tabular}{|c|c|c|}
\hline \multirow{2}{*}{\multicolumn{3}{|c|}{$0.0 \mathrm{~g}$ gi $|675594620| \mathrm{gb}|\mathrm{KJ} 923002.1|$ Escherichia coli strain bla $\mathrm{TEM}\left(\mathrm{bla}_{\mathrm{TEM}-1}\right)$ India }} \\
\hline & & \\
\hline 0.0014 & 0.0027 & - $\mathbf{\Delta}$ gi|383282208|gb|JQ823175.1| Escherichia beta-lactamase TEM (bla ${ }_{\mathrm{TEM}}$ ) India \\
\hline & шTEM E.coli Egypt & \\
\hline & 0.0041 & A g1|34/810/16|gD||Ni88365.1| Escherichia coll strain AKY 4 Dla TEM gene India \\
\hline
\end{tabular}

(b)

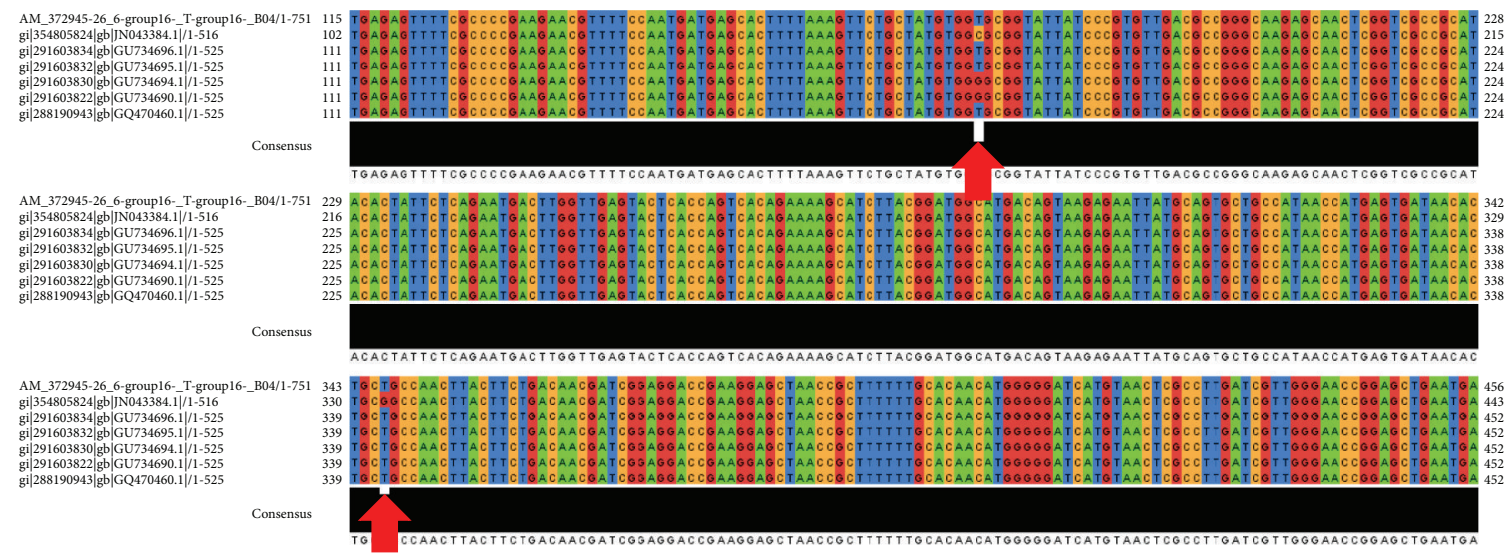

(c)

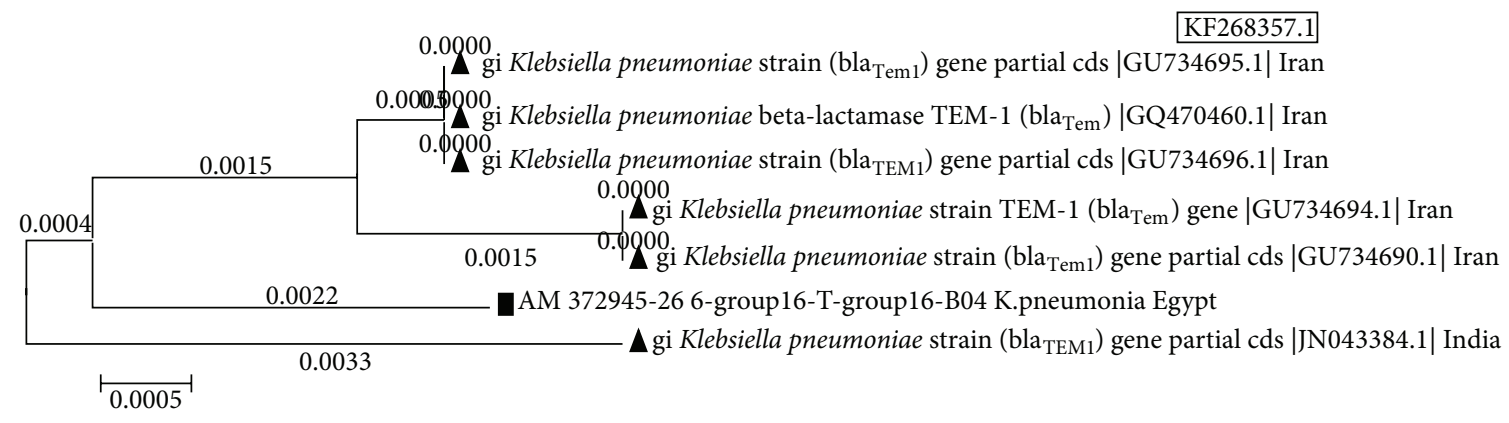

(d)

FIGURE 4: The multiple sequences alignments and trees of TEM gene $\left(b l a_{\mathrm{TEM} 1,2}\right)$ in different bacterial species. (a) TEM gene in E. coli strains isolated from ZU Hospitals in comparison with published TEM gene of $E$. coli strains from GenBank. (b) A phylogenetic tree of TEM gene of $E$. coli isolated from ZU Hospitals and published homologous ones in GenBank. (c) The multiple sequences alignments of gene in K. pneumoniae strains isolated from ZU Hospitals in comparison with published TEM gene in K. pneumoniae strains from GenBank. (d) Phylogenetic tree of sequence of K. pneumoniae isolated from ZU Hospitals and published homologous ones in GenBank. 


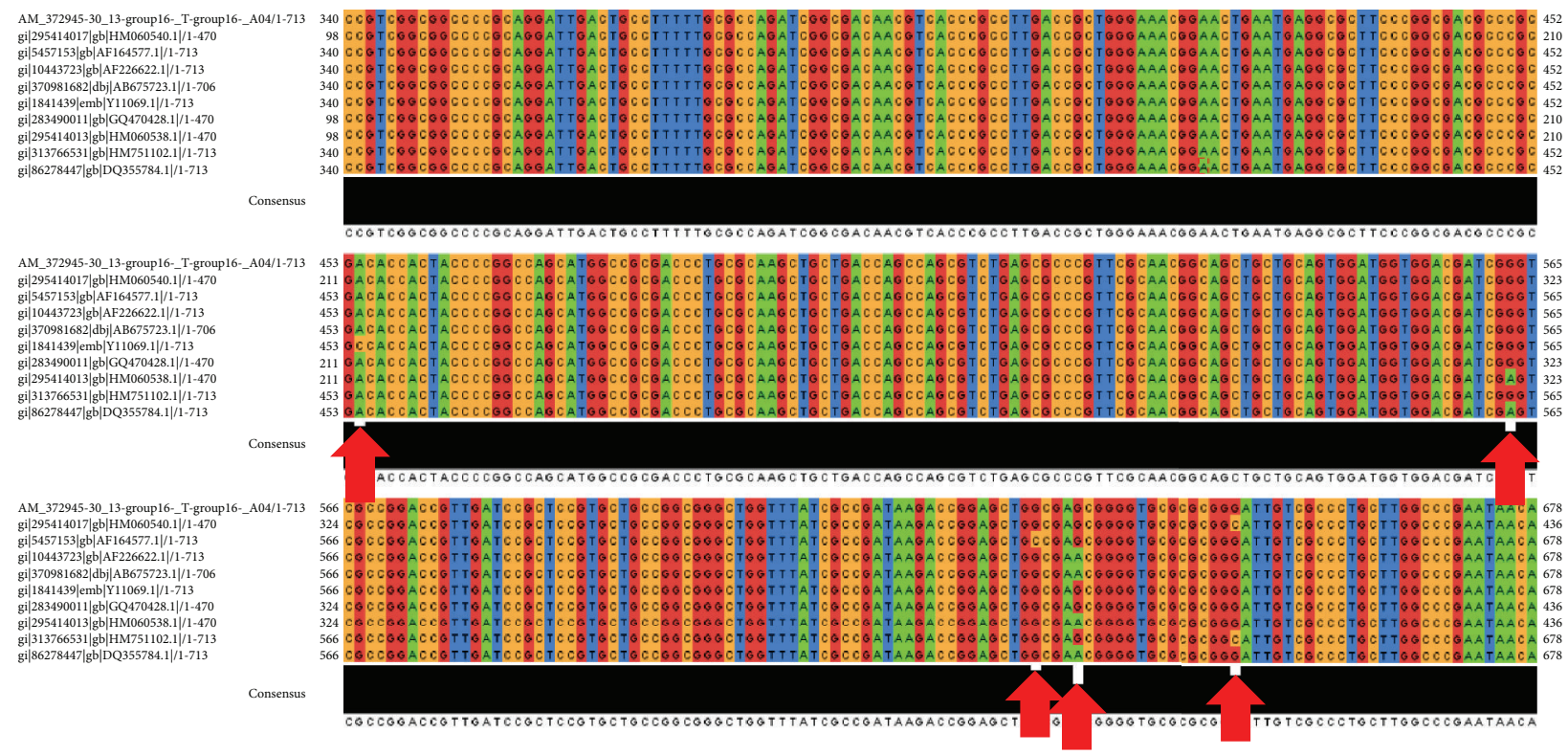

(a)

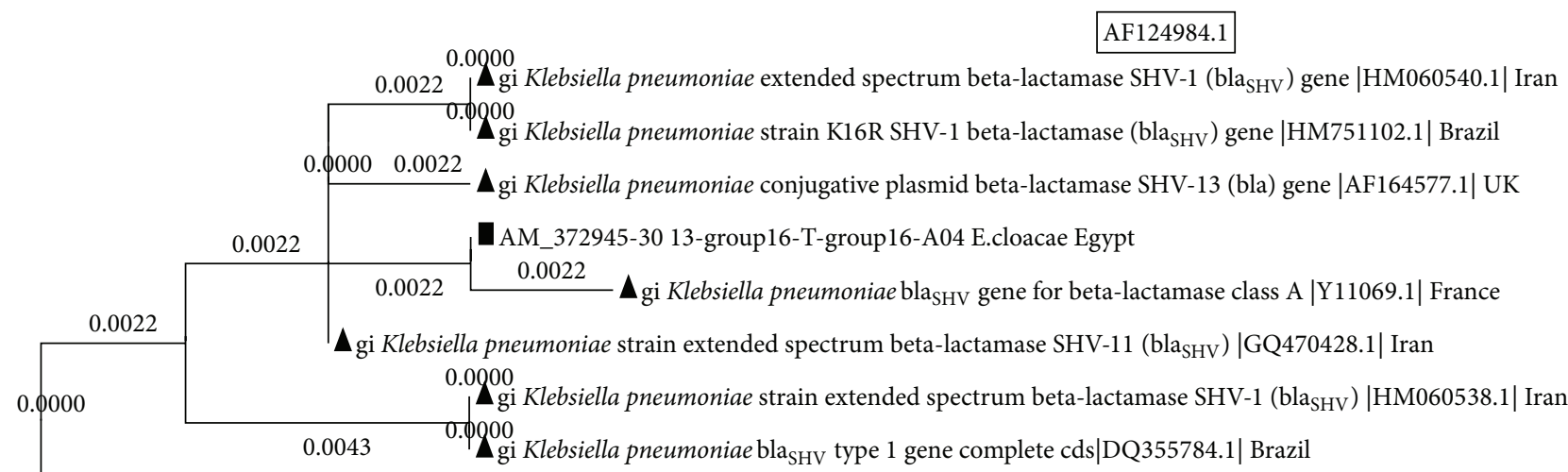

$\Delta$ gi Klebsiella pneumoniae beta-lactamase SHV-14 (bla) gene |AF226622.1| UK

0.0087

A gi Klebsiella pneumoniae plasmid bla ${ }_{S H V}$ gene for beta-lactamase SHV |AB675723.1| Japan

$\longmapsto$

(b)

FIGURE 5: The multiple sequences alignments and trees of SHV gene in different species. (a) SHV gene in K. pneumoniae strains isolated from ZU Hospitals in comparison with published SHV gene of K. pneumoniae strains from GenBank. (b) Phylogenetic tree of SHV sequence of $K$. pneumoniae isolated from ZU Hospitals and published homologous ones in GenBank.

sequence of $E$. coli isolated from Zagazig University Hospitals and published homologous ones in GenBank showed dissimilarity degree between Egyptian and other universal strains (Figure 6(b)).

(2) CTX-M-1 Gene (bla $\left.{ }_{C T X-M-1}\right)$ of Klebsiella pneumoniae Strains. The alignment in this case showed 39 different common SNPs between the different strains. The SNPs positions were indicated in positions $1 \rightarrow 39$ (Figure 6(c)). A phylogenetic tree of CTX-M-1 gene sequence in K. pneumoniae strains, isolated from ZU Hospitals, and published homologous sequences in GenBank showed different degrees of dis/similarity between the different strains with many unique sequences in Egyptian strain (Figure 6(d)).

(3) CTX-M-1 Gene (bla CTX-M-1 $_{1}$ of Pseudomonas aeruginosa Strains. The CTX-M-1 gene isolated from $P$. aeruginosa strains in Zagazig University Hospitals was compared using BLAST program with published CTX-M-1 gene in $P$. aeruginosa strains from GenBank (e.g., P.aeruginosa KC571255.1). The results showed 4 different common SNPs between the different strains. The SNPs positions were indicated in 117, 206, 228, and 283 (Figure 6(e)). A phylogenetic tree showed similarity degree between Egyptian and Russian strains (Figure 6(f)). 


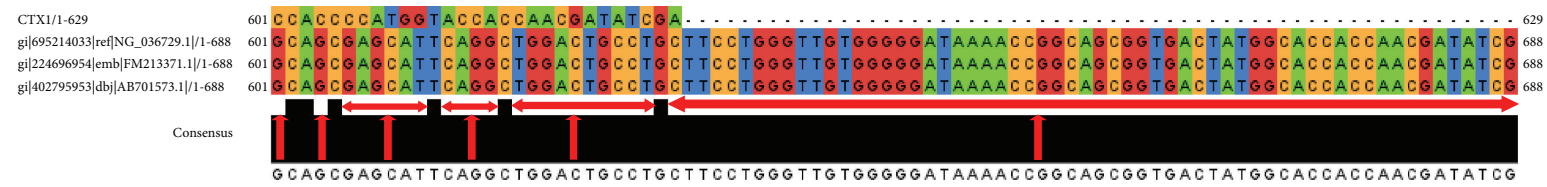

(a)

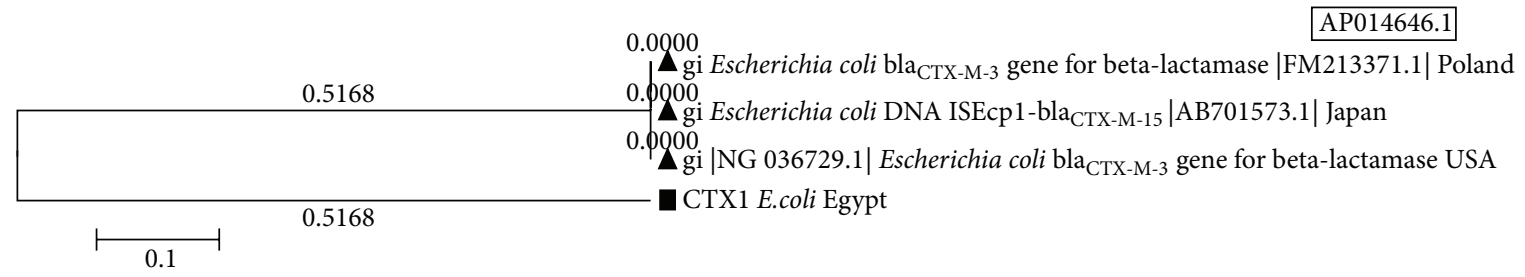

(b)

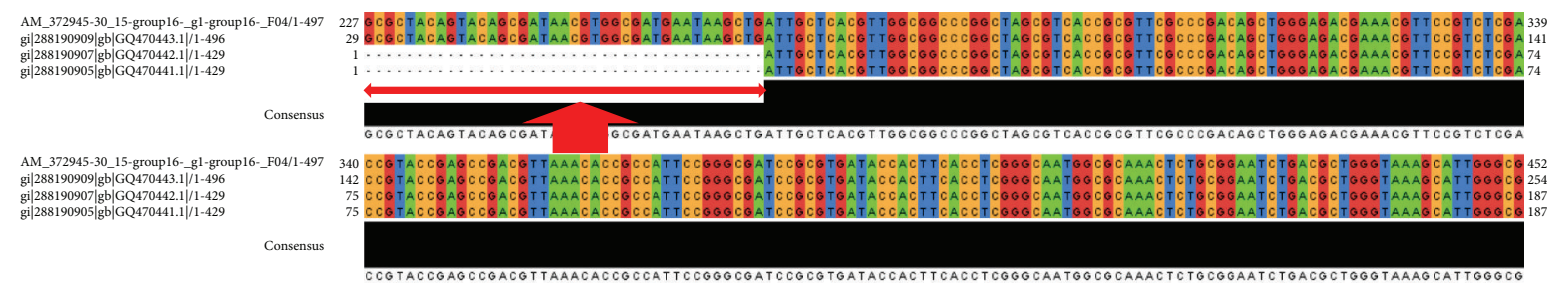

(c)

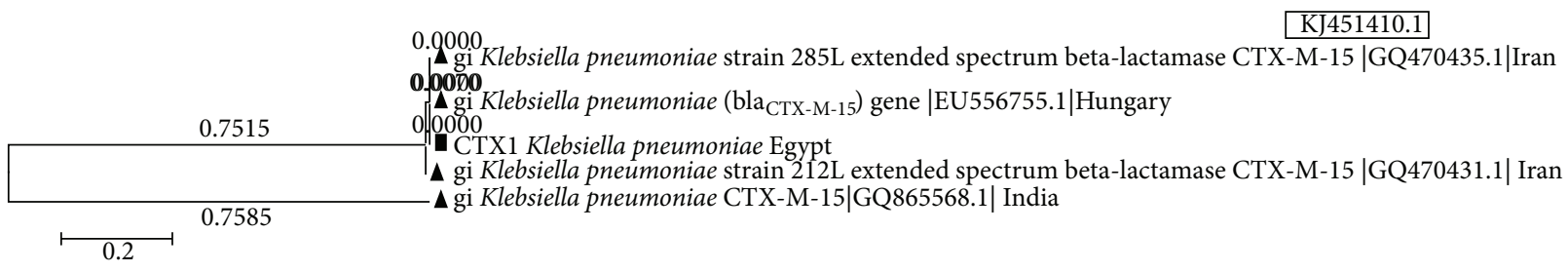

(d)

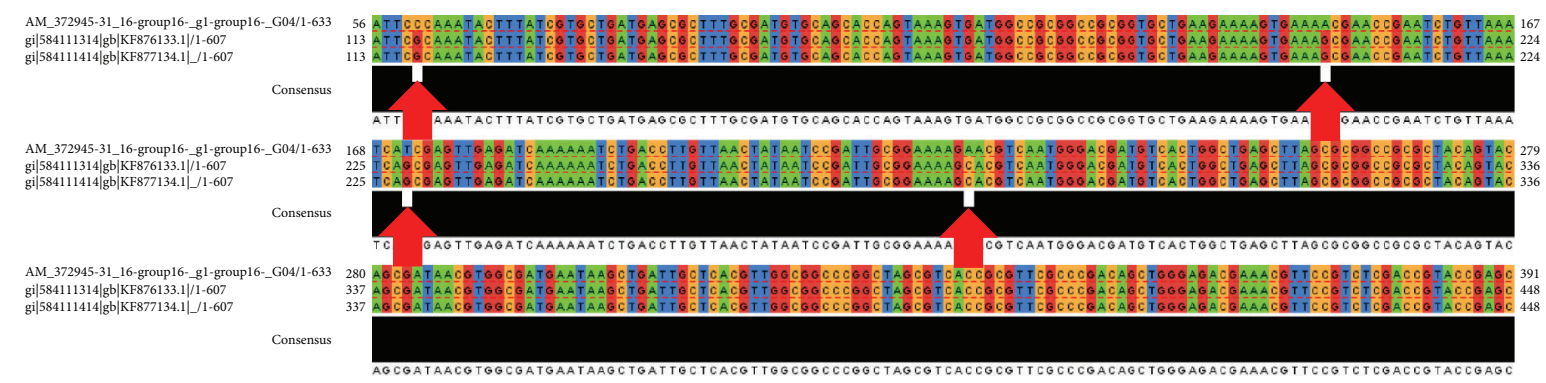

(e)

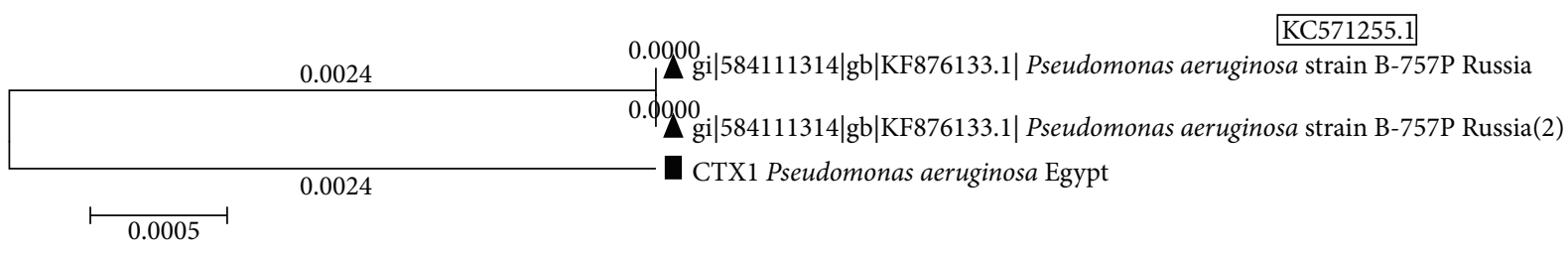

(f)

FigurE 6: The multiple sequences alignments and trees of CTX-M-1 gene in different species. (a) CTX-M-1 gene in E. coli strains isolated from ZU Hospitals in comparison with published CTX-M-1 gene of E. coli strains from GenBank. (b) A tree of CTX-M-1 sequence of E. coli isolated from ZU Hospitals and published homologs in GenBank. (c) The multiple sequences alignments of CTX-M-1 gene in K. pneumoniae strains isolated from ZU Hospitals in comparison with published CTX-M-1 gene in K. pneumoniae strains from GenBank. (d) Phylogenetic tree of CTX-M-1 sequence of K. pneumoniae isolated from ZU Hospitals and published homologous sequences in GenBank. (e) Multiple sequences alignments of CTX-M-1 gene in P. aeruginosa strains isolated from ZU Hospitals in comparison with published CTX-M-1 gene in P. aeruginosa strains from GenBank. (f) Phylogenetic tree of CTX-M-1 sequence of P. aeruginosa isolated from ZU Hospitals and published homologs in GenBank. 


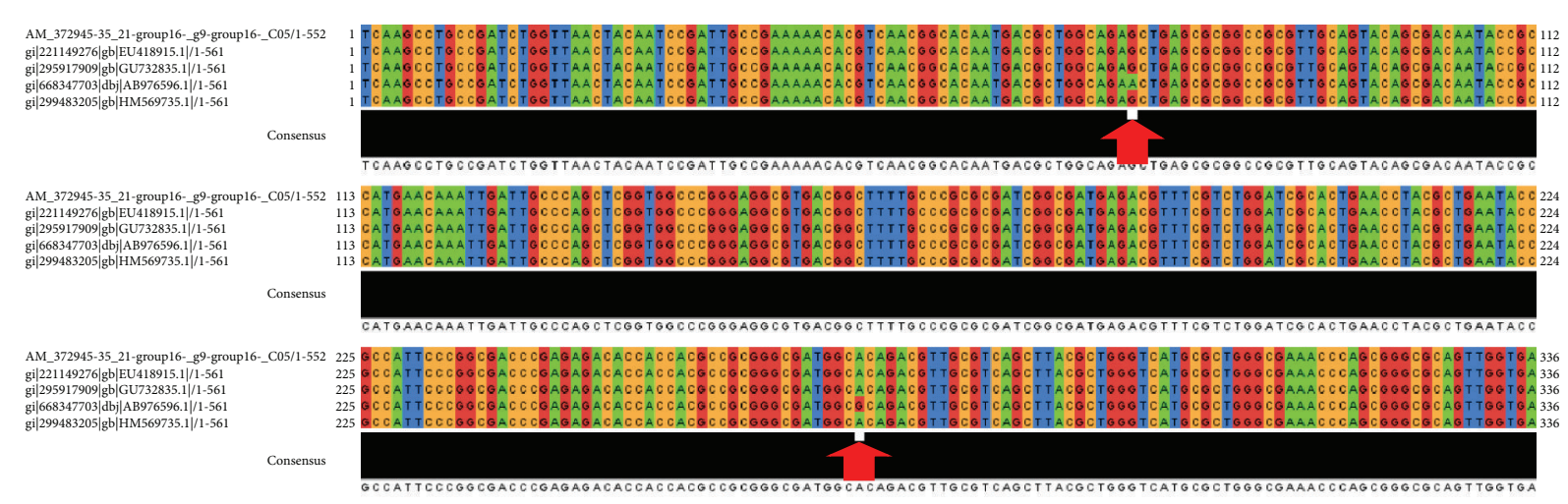

(a)

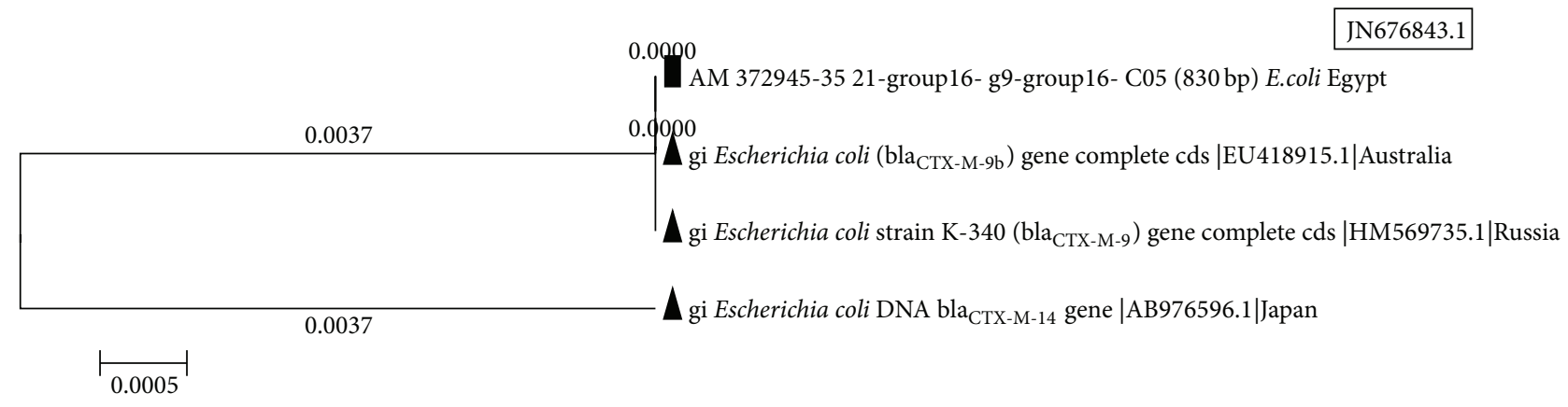

(b)

Figure 7: The multiple sequences alignments and tree of CTX-M-9 gene in different species. (a) CTX-M-9 gene in E. coli strains isolated from ZU Hospitals in comparison with published CTX-M-9 gene of E. coli strains from GenBank. (b) Phylogenetic tree of CTX-M-9 sequence of E. coli isolated from ZU Hospitals and published homologous ones in GenBank.

3.4.5. The Analysis of CTX-M-9 Gene (bla $\left.a_{\text {СТХ-М-9 }}\right)$ in Escherichia coli Strains. The CTX-M-9 gene isolated from E. coli strains in Zagazig University Hospitals was compared with published CTX-M-1 gene in P. aeruginosa strains from GenBank using BLAST program (e.g., E. coli JN676843.1). The multiple sequences alignments showed 2 different common SNPs in positions 74 and 272 (Figure 7(a)). The phylogenetic tree of CTX-M-9 gene sequence in $E$. coli strains, isolated from ZU Hospitals, and published homologous sequences in GenBank showed different degrees of dis/similarity between the different strains and many unique sequences in the Egyptian strain similar to that of Russia and Australia and dissimilar to that of Japan (Figure 7(b)).

\section{Discussion}

The Gram-negative bacilli are among the most important causes of serious nosocomial and community-onset bacterial infections in humans and antimicrobial resistance has become a global threat to effective health care delivery [14]. However, carbapenem-resistant Gram-negative bacilli have been increasingly reported worldwide [4]. Various acquired carbapenemases have been identified in the last years, belonging to either acquired metallo-beta-lactamases (IMP, VIM,
TABLE 2: The distribution of Gram-negative bacilli isolates in each clinical specimen.

\begin{tabular}{lccc}
\hline \multicolumn{2}{c}{ Clinical specimens } & \multicolumn{2}{c}{ Gram-negative bacilli isolates } \\
Type & Number & Number & $(\%)$ \\
\hline Urine & 52 & 41 & 78.8 \\
Blood & 18 & 12 & 66.6 \\
Sputum & 29 & 10 & 34.5 \\
Pus & 9 & 2 & 22.2 \\
\hline Total & $\mathbf{1 0 8}$ & $\mathbf{6 5}$ & $\mathbf{( 6 0 . 2} \%)$ \\
\hline
\end{tabular}

$\chi^{2}=21.28, P<0.001$ (statistically significant).

SPM, GIM, NDM, and DIM types) or class A (KPC and GES) and class D $\beta$-lactamase OXA-48 [15].

In the present study, prevalence of $\beta$-lactamasesproducing isolates was found in Table 2. Different studies carried out by other workers in various parts of the world show quite variable results. In a study carried out, the frequency of beta-lactamases-producing isolates was urine (61\%), followed by blood cultures (38\%), wound swabs (13\%), and tracheal aspirates $(5 \%)(P<0.001)$ [16]. And this is similar to our study. By contrast, Shanthi and Sekar [17] in India reported that Gram-negative isolates were obtained from the respiratory tract $(41.8 \%)$ followed by urinary tract 
TABLE 3: API 20E identification of Gram-negative bacilli isolates among positive clinical specimens.

\begin{tabular}{lcc}
\hline Organism & \multicolumn{2}{c}{ Total =65 } \\
\hline Escherichia coli & Number & $(\%)$ \\
Klebsiella pneumoniae & 30 & 46.1 \\
Enterobacter cloacae & 17 & 26.2 \\
Pseudomonas aeruginosa & 4 & 6.1 \\
Proteus mirabilis & 7 & 10.7 \\
Acinetobacter baumanii & 2 & 3.07 \\
Citrobacter freundii & 3 & 4.6 \\
Proteus vulgaris & 1 & 1.5 \\
\hline P<0.001 (staticaly & 1 & 1.5 \\
\hline
\end{tabular}

$P<0.001$ (statistically significant).

(25.5\%), wound $(20 \%)$, and blood (12.7\%). Also, pus was the most common specimen accounting for $21 \%$ followed by tracheal aspirate (17\%), sputum (16\%), urine (11\%), and blood (7\%) [18].

Various risk factors of $\beta$-lactamases have been implicated in selection and spread producing strains from various clinical samples.

In accordance with distribution of Gram-negative bacilli, (46.1\%) Escherichia coli and (26.2\%) Klebsiella pneumoniae isolates followed by (10.7\%) P. aeruginosa were identified as the commonest isolates among Gram-negative bacilli (Table 3) and this coincided with that concluded by Sahu et al. [19] who found that $58 \%$ were identified as Escherichia coli followed by $27.7 \%$ Klebsiella pneumoniae and $15 \%$ Pseudomonas aeruginosa in Udaipur, Rajasthan. In a study by Vipin et al. [20] 52 (58.42\%) isolates of Escherichia coli were found to be the most common organisms in Allahabad followed by Klebsiella pneumoniae (20.22\%), Pseudomonas aeruginosa (12.35\%), Proteus vulgaris (3.37\%), Proteus mirabilis (2.24\%), and Enterobacter cloacae (2.24\%). Also, in India, Sankarankutty and Kaup [21] documented the same result in that $58.42 \%$ isolates of Escherichia coli were found to be the most common organisms followed by Klebsiella pneumoniae (20.22\%), Pseudomonas aeruginosa (12.35\%), Proteus vulgaris (3.37\%), Proteus mirabilis (2.24\%), and Enterobacter aerogenes $(2.24 \%)$.

But our study disagreed with that published by Aboderin et al. [22] who reported that Pseudomonas aeruginosa recorded the highest prevalence followed by Klebsiella pneumoniae and ESBL producers, whereas frequency among $E$. coli isolates was much lower than Klebsiella pneumoniae. Hence, prevalence of pathogens often varies dramatically between communities according to geography, hospitals in the same community and among different patient populations in the same hospital.

In this study, risk factors associated with isolation of Gram-negative bacilli isolates were shown in Table 4. And this was matched with that reported by Kumar et al. [23] who exhibited major risk factors such as prolonged hospitalization $>8$ days, previous antibiotic use, trauma, and mechanical ventilation which may contribute to the mortality.
In Turkey, Aktas et al. [24] reported risk factors for acquisition including prolonged hospitalization, an ICU stay, ventilator usage, previous use of carbapenem antibiotics, and the presence of underlying diseases and this is compatible with our research. But in Brazil, Tuon et al. [25] documented that there was statistical significance in isolation of Klebsiella pneumoniae isolates according to age $(P=0.005)$ and mechanical ventilation $(P=0.003)$, while trauma $(P=0.87)$ and ICU stay $(P=0.25)$ had a statistical significance as major risk factors.

The importance of these risk factors lies in the epidemiological implications at the hospital level because the results suggest a probable nosocomial transmission of the infection.

Resistance pattern among nosocomial bacterial pathogens may vary widely from country to country at any time and within the same country over time [26].

In our study, all the isolates were resistant to cefotaxime (100\%) and displayed unusually high level of imipenemresistance $(50.8 \%)$ isolates with MICs ranging from 15.6 to $250 \mu \mathrm{g} / \mathrm{mL}$ (Table 5) $(P<0.001)$. In Egypt, this was parallel to that reported by Mohamed and Raafat [27] who reported (52.2\%) imipenem-resistance among isolates, (100\%) cefotaxime resistance, (55\%) susceptible-ciprofloxacin, and (70\%) susceptibility to amikacin. In the Middle East, the occurrence of imipenem-resistant Gram-negative bacilli is alarmingly elevated. Another similar study showed that all 84 Klebsiella pneumoniae isolates exhibited resistance to imipenem with MICs ranging from 4 to $>32 \mu \mathrm{g} / \mathrm{mL}$ in a Greek hospital [28].

Another dissimilar study was shown in Saudi Arabia, where the susceptibility rate of Gram-negative organisms isolated from a tertiary care hospital to imipenem was reported to be as low as 10\% [29]. Galani et al. [30] reported that Klebsiella pneumoniae and Escherichia coli isolates were found to be susceptible to imipenem in routine susceptibility disk diffusion tests. Other authors observed that all beta-lactamases producers of Escherichia coli, Klebsiella pneumoniae, and Pseudomonas aeruginosa were susceptible to imipenem showing coresistance to other antibiotics of aminoglycosides, fluoroquinolones, and others [17]. The extensive use of carbapenems in some locations has likely created a selective antibiotic pressure which in turn has resulted in an increased prevalence of carbapenem-resistant Gram-negative isolates.

The carbapenem resistance due to production of $\beta$ lactamases has a potential for rapid dissemination, since it is often plasmid-mediated [2]. Consequently, rapid detection of $\beta$-lactamases is necessary to initiate effective infection control measures to prevent their uncontrolled spread in clinical settings. In Egyptian hospitals the $\beta$-lactamases presence was confirmed by PCR amplification.

In our study, the percentage of $b l a_{\mathrm{VIM}}, b l a_{\mathrm{TEM}}, b l a_{\mathrm{SHV}}$, and $b l a_{\mathrm{CTX}-\mathrm{M}}$ genes among Gram-negative bacilli isolates was shown in Table 6 . As regards $b l a_{\mathrm{VIM}}$ gene detected in our results it is similar to that $b l a_{\mathrm{VIM}}$ gene encoding MBL among the isolates of $P$. aeruginosa (61.3\%) in Tehran hospitals [31]. On the contrary, bla $a_{\mathrm{VIM}}$ genes were not detected among the studied Gram-negative isolates in other Tehran hospitals [32]. TEM, SHV, and CTX-M genes are the most common plasmid-mediated lactamases often found in 
TABLE 4: Risk factors associated with isolation of Gram-negative bacilli isolates.

\begin{tabular}{|c|c|c|c|c|}
\hline Risk factor & $\begin{array}{l}\text { Gram-negative } \\
\text { bacilli isolates }\end{array}$ & $\begin{array}{c}\text { Total number of } \\
\text { samples }\end{array}$ & Relative risk $(95 \% \mathrm{CI})^{*}$ & $P$ value significance \\
\hline \multicolumn{5}{|l|}{ Age } \\
\hline$<40$ & 26 & 45 & \multirow{2}{*}{$1.07(0.78-1.47)$} & \multirow{2}{*}{0.66} \\
\hline$>40$ & 39 & 63 & & \\
\hline \multicolumn{5}{|l|}{ Sex } \\
\hline Male & 29 & 49 & \multirow{2}{*}{$1.09(0.8-1.47)$} & \multirow{2}{*}{0.59} \\
\hline Female & 36 & 59 & & \\
\hline \multicolumn{5}{|l|}{ Trauma } \\
\hline Yes & 48 & 59 & \multirow{2}{*}{$2.34(1.57-3.51)$} & \multirow{2}{*}{$<0.001$} \\
\hline No & 17 & 49 & & \\
\hline \multicolumn{5}{|c|}{ Hospitalization length other than ICU } \\
\hline$<7$ days & 15 & 51 & \multirow{2}{*}{$2.98(1.33-4.61)$} & \multirow{2}{*}{$<0.001$} \\
\hline >7 days & 50 & 57 & & \\
\hline \multicolumn{5}{|c|}{ ICU admission } \\
\hline Yes & 28 & 46 & \multirow{2}{*}{$1.02(0.45-2.47)$} & \multirow{2}{*}{$<0.001$} \\
\hline No & 37 & 62 & & \\
\hline \multicolumn{5}{|c|}{ Urinary catheter } \\
\hline Yes & 18 & 32 & \multirow{2}{*}{$0.91(0.64-1.29)$} & \multirow{2}{*}{0.58} \\
\hline No & 47 & 76 & & \\
\hline \multicolumn{5}{|c|}{ Ventilator support } \\
\hline Yes & 10 & 18 & \multirow{2}{*}{$\mathbf{0 . 8 3}(0.51-1.35)$} & \multirow{2}{*}{0.44} \\
\hline No & 20 & 30 & & \\
\hline \multicolumn{5}{|c|}{ Central venous catheter } \\
\hline Yes & 4 & 9 & \multirow{2}{*}{$\mathbf{0 . 6 7}(0.31-1.43)$} & \multirow{2}{*}{0.26} \\
\hline No & 26 & 39 & & \\
\hline
\end{tabular}

$*=95 \%$ confidence interval.

TABle 5: Antimicrobial susceptibility patterns by disc diffusion method.

\begin{tabular}{|c|c|c|c|c|c|c|}
\hline \multirow{3}{*}{ Antibiotic } & \multicolumn{6}{|c|}{ Antimicrobial susceptibility patterns of all Gram-negative bacilli isolates } \\
\hline & \multicolumn{2}{|c|}{ Susceptible } & \multicolumn{2}{|c|}{ Intermediate } & \multicolumn{2}{|c|}{ Resistant } \\
\hline & Number & $(\%)$ & Number & $(\%)$ & Number & $(\%)$ \\
\hline Imipenem & 31 & 47.7 & 1 & 1.5 & 33 & 50.8 \\
\hline Amikacin & 40 & *61.5 & 1 & 1.5 & 24 & 44.6 \\
\hline Ciprofloxacin & 35 & 53.8 & 3 & 4.6 & 27 & 41.5 \\
\hline Piperacillin & 15 & 23.1 & 6 & ${ }^{*} 9.2$ & 44 & 67.7 \\
\hline Cefoperazone/sulbactam & 21 & 32.3 & 4 & 6.1 & 40 & 61.5 \\
\hline Cefoxitin & 12 & 18.4 & 0 & 0.00 & 53 & 81.5 \\
\hline Cefotaxime & 0 & 0.00 & 0 & 0.00 & 65 & ${ }^{*} 100.00$ \\
\hline
\end{tabular}

${ }^{*} P<0.001$ (statistically significant).

Enterobacteriaceae and $P$. aeruginosa [33]. In Iran, Eftekhar et al. [34] showed $69.3 \% b l a_{\mathrm{TEM}}$ and $31.37 \% b l a_{\mathrm{CTX}-\mathrm{M}-1}$ genes among Gram-negative isolates and this agreed with our study. Also, presence of $b l a_{\mathrm{CTX}-\mathrm{M} 1,9}, a_{\mathrm{SHV}}$, and $b l a_{\mathrm{TEM}}$ genes among tested rods of the Enterobacteriaceae family was revealed by Ojdana et al. [35]. Another study reported by Cuzon et al. [36] harbored similar results regarding carbapenem-resistant Gram-negative isolates carrying TEM, SHV, CTX-M-1, and CTX-M-9 genes.
In Switzerland, Zurfluh et al. [37] mentioned that the isolates of Enterobacteriaceae were further screened for bla genes encoding SHV, TEM, CTX-M group 1, CTX-M group 2, or CTX-M group 9 enzymes with (23\%), (71.3\%), (39.2\%), $(20.1 \%)$, and $(15.6 \%)$, respectively.

Other authors noted different observations in that clinical isolates of Escherichia coli and Pseudomonas aeruginosa carried $b l a_{\text {CTX-M-types }}$ which was the most common $(95.8 \%)$ followed by $b l a_{\mathrm{TEM}}(29.2 \%), b l a_{\mathrm{SHV}}(7.3 \%)$, and $b l a_{\mathrm{VIM}}$ 
TABLE 6: The percentage of $b l a_{\mathrm{VIM}}, b l a_{\mathrm{TEM}}, b l a_{\mathrm{SHV}}$, and $b l a_{\mathrm{CTX}-\mathrm{M}}$ genes among Gram-negative bacilli isolates.

\begin{tabular}{|c|c|c|c|c|c|c|c|c|c|c|c|c|c|}
\hline \multicolumn{2}{|l|}{ Isolates } & \multicolumn{12}{|c|}{$\beta$-lactamases genes } \\
\hline \multirow{2}{*}{ Organism } & \multirow{2}{*}{ Number } & \multicolumn{2}{|c|}{ VIM } & \multicolumn{2}{|c|}{ TEM } & \multicolumn{2}{|c|}{ SHV } & \multicolumn{2}{|c|}{ CTX-M-1 } & \multicolumn{2}{|c|}{ CTX-M-9 } & \multicolumn{2}{|c|}{ CTX-M-8/25 } \\
\hline & & Number & $(\%)$ & Number & $(\%)$ & Number & $(\%)$ & Number & $(\%)$ & Number & $(\%)$ & Number & $(\%)$ \\
\hline Escherichia coli & 15 & 10 & 66.6 & 13 & 87.0 & 0 & 0.0 & 3 & 20.0 & 4 & 26.6 & 0 & 0.00 \\
\hline Klebsiella pneumonia & 10 & 8 & 80.0 & 9 & 90.0 & 5 & 50 & 6 & 60.0 & 1 & 10.0 & 0 & 0.00 \\
\hline Enterobacter cloaca & 2 & 1 & 50.0 & 1 & 50.0 & 0 & 0.0 & 0 & 0.00 & 0 & 0.00 & 0 & 0.00 \\
\hline Pseudomonas aeruginosa & 4 & 2 & 50.0 & 1 & 25.0 & 0 & 0.0 & 3 & 75.0 & 1 & 25.0 & 0 & 0.00 \\
\hline Proteus mirabilis & 1 & 0 & 0.00 & 0 & 0.00 & 0 & 0.0 & 0 & 0.00 & 0 & 0.00 & 0 & 0.00 \\
\hline Acinetobacter baumanii & 1 & 1 & 100 & 0 & 0.00 & 0 & 0.0 & 0 & 0.00 & 0 & 0.00 & 0 & 0.00 \\
\hline Total & 33 & 22 & 66.7 & 24 & 72.7 & 5 & 15.0 & 12 & 36.0 & 6 & 18.2 & $\mathbf{0}$ & 0.00 \\
\hline
\end{tabular}

(12.5\%) in Nepal [38]. These observations contribute to the knowledge of the epidemiology of VIM, TEM, SHV, and CTX-M-producing Gram-negative isolates that have now become endemic in major hospitals in Egypt. Continuous monitoring, proper infection control, and surveillance and prevention practices will limit the further spread of these infections within these hospitals and clinical settings.

Multiple sequences analysis is used in such biological studies to extract important phylogenetic and evolutionary information using different scoring matrices (BLOSUM62 for BLAST, BLOSUM50 for SEARCH and FASTA) [39].

\section{Conclusion}

There is a high prevalence of $\beta$-lactamase genes in our clinical isolates that are responsible for such resistance. Hence, it is essential to report $\beta$-lactamases production along with routine sensitivity reports, which will help the clinician in prescribing proper antibiotics. Also, the sequence analysis of amplified genes showed differences between multiple SNPs in the same gene among different local isolates and with internationally published sequences. In the end, it has been felt that there is a need to formulate strategies to detect and prevent the emergence of $\beta$-lactamases producing strains for the effective treatment of infections which are caused by them.

\section{Conflict of Interests}

The authors have declared no conflict of interests and they have no financial conflicts.

\section{Acknowledgments}

The authors would like to express their sincere thanks and deepest gratitude to Professor Dr. Ahmed Mansour Al Zohairy, Assistant Professor of genetics, Faculty of Agriculture, Zagazig University, for his help in achieving and planning bioinformatics of sequences.

\section{References}

[1] J. Breslow, "Illinois 'Nightmare Bacteria' Outbreak Raises Alarms," April 2014, http://www.pbs.org.

[2] H. M. Zowawi, H. H. Balkhy, T. R. Walsh, and D. L. Paterson, “ $\beta$ Lactamase production in key gram-negative pathogen isolates from the Arabian Peninsula," Clinical Microbiology Reviews, vol. 26, no. 3, pp. 361-380, 2013.

[3] J. N. Kattan, M. V. Villegas, and J. P. Quinn, "New developments in carbapenems," Clinical Microbiology and Infection, vol. 14, no. 12, pp. 1102-1111, 2008.

[4] K. M. Papp-Wallace, A. Endimiani, M. A. Taracila, and R. A. Bonomo, "Carbapenems: past, present, and future," Antimicrobial Agents and Chemotherapy, vol. 55, no. 11, pp. 4943-4960, 2011.

[5] H. Lee, K. S. Ko, J.-H. Song, and K. R. Peck, "Antimicrobial activity of doripenem and other carbapenems against gramnegative pathogens from Korea," Microbial Drug Resistance, vol. 17, no. 1, pp. 37-45, 2011.

[6] M. A. Toleman and T. R. Walsh, "Evolution of the ISCR3 group of ISCR elements," Antimicrobial Agents and Chemotherapy, vol. 52, no. 10, pp. 3789-3791, 2008.

[7] S. A. Jemima and S. Verghese, "Multiplex PCR for $b l a_{\mathrm{CTX}-\mathrm{M}}$ and $b l a_{\mathrm{SHV}}$ in the extended spectrum-B-lactamase (ESBL) producing gram-negative isolates," The Indian Journal of Medical Research, vol. 128, no. 3, pp. 313-317, 2008.

[8] R. C. Picão, L. Poirel, A. C. Gales, and P. Nordmann, "Diversity of $\beta$-lactamases produced by ceftazidime-resistant Pseudomonas aeruginosa isolates causing bloodstream infections in Brazil," Antimicrobial Agents and Chemotherapy, vol. 53, no. 9, pp. 3908-3913, 2009.

[9] E. S. Moland, J. A. Black, J. Ourada, M. D. Reisbig, N. D. Hanson, and K. S. Thomson, "Occurrence of newer $\beta$-lactamases in Klebsiella pneumoniae isolates from 24 U.S. Hospitals," Antimicrobial Agents and Chemotherapy, vol. 46, no. 12, pp. 3837-3842, 2002.

[10] L. K. Dianna and H. G. Peter, "Pseudomonas," in Manual of Clinical Microbiology, R. M. Patrick, J. B. Ellen, H. J. James, A. P. Miccael, and H. Y. Robert, Eds., vol. 1, pp. 719-728, ASM Press, Washington, DC, USA, 8th edition, 2003.

[11] Clinical and Laboratory Standards Institute, Performance Standards for Antimicrobial Susceptibility Testing; Twenty-Second Informational Supplement, CLSI M100-S22, Clinical and Laboratory Standards Institute, Wayne, Pa, USA, 2012.

[12] C. Dallenne, A. da Costa, D. Decre, C. Favier, and G. Arlet, "Development of a set of multiplex PCR assays for the detection 
of genes encoding important $\beta$-lactamases in Enterobacteriaceae," Journal of Antimicrobial Chemotherapy, vol. 65, no. 3, Article ID dkp498, pp. 490-495, 2010.

[13] S. F. Altschul, W. Gish, W. Miller, E. W. Myers, and D. J. Lipman, "Basic local alignment search tool," Journal of Molecular Biology, vol. 215, no. 3, pp. 403-410, 1990.

[14] J. D. D. Pitout, "Multiresistant enterobacteriaceae: new threat of an old problem," Expert Review of Anti-Infective Therapy, vol. 6, no. 5, pp. 657-669, 2008.

[15] J. Manuel, R. Martinez, P. Nordmann, N. Fortineau, and L. Poirel, "VIM-19, a metallo- $\beta$-lactamase with increased carbapenemase activity from Escherichia coli and Klebsiella pneumoniae," Antimicrobial Agents and Chemotherapy, vol. 54, no. 1, pp. 471-476, 2010.

[16] J.-M. Rodriguez-Martinez, P. Nordmann, N. Fortineau, and L. Poirel, "VIM-19, a metallo- $\beta$-lactamase with increased carbapenemase activity from Escherichia coli and Klebsiella pneumoniae," Antimicrobial Agents and Chemotherapy, vol. 54, no. 1, pp. 471-476, 2010.

[17] M. Shanthi and U. Sekar, "Extended spectrum beta lactamase producing Escherichia coli and Klebsiella pneumoniae: risk factors for infection and impact of resistance on outcomes," Journal of the Association of Physicians of India, vol. 58, no. 1, pp. 41-44, 2010.

[18] K. K. Benachinmardi, M. Padmavathy, J. Malini, and B. V. Naveneeth, "Prevalence of non-fermenting Gram-negative bacilli and their in vitro susceptibility pattern at a tertiary care teaching hospital," Journal of the Scientific Society, vol. 41, no. 3, pp. 162166, 2014.

[19] S. K. Sahu, A. S. Dalal, and G. Bansal, "Detection of extendedspectrum $\beta$-lactamases in clinical isolates of E. coli and Klebsiella species from Udaipur Rajasthan," Biomedical Research, vol. 22, no. 3, pp. 367-373, 2011.

[20] K. Vipin, K. M. Rohit, C. Avantika, and G. Pramila, "Incidence of $\beta$-lactamase producing gram-negative clinical isolates and their antibiotic susceptibility pattern: a case study in Allahabad," International Journal of Research in Pure and Applied Microbiology, vol. 1, no. 3, pp. 36-39, 2011.

[21] J. Sankarankutty and S. Kaup, "Microbiological profile and antibiogram of uropathogens from a tertiary care centre in Tumkur, India," Journal of Microbiology and Biotechnology Research, vol. 4, no. 2, pp. 46-51, 2014.

[22] O. A. Aboderin, L.-R. Abdu, B. W. Odetoyin, and A. Lamikanra, "Antimicrobial resistance in Escherichia coli strains from urinary tract infections," Journal of the National Medical Association, vol. 101, no. 12, pp. 1268-1273, 2009.

[23] S. H. Kumar, A. S. De, S. M. Baveja, and M. A. Gore, "Prevalence and risk factors of Metallo $\beta$-lactamase producing Pseudomonas aeruginosa and Acinetobacter species in burns and surgical wards in a tertiary care hospital," Journal of Laboratory Physicians, vol. 4, no. 1, pp. 39-42, 2012.

[24] Z. Aktas, D. Satana, C. Kayacan et al., "Carbapenem resistance in Turkey: repeat report on OXA-48 in Klebsiella pneumoniae and first report on IMP-1 beta-lactamase in Escherichia coli," African Journal of Microbiology Research, vol. 6, no. 17, pp. 38743878, 2012.

[25] F. F. Tuon, J. L. Rocha, P. Toledo et al., "Risk factors for KPCproducing Klebsiella pneumoniae bacteremia," Brazilian Journal of Infectious Diseases, vol. 16, no. 5, pp. 416-419, 2012.

[26] K. Prashanth and S. Badrinath, "In vitro susceptibility pattern of Acinetobacter species to commonly used cephalosporins, quinolones, and aminoglycosides," Indian Journal of Medical Microbiology, vol. 22, no. 2, pp. 97-103, 2004.

[27] N. M. Mohamed and D. Raafat, "Phenotypic and genotypic detection of metallo-beta-lactamases in imipenem-resistant Acinetobacter baumannii isolated from a tertiary hospital in Alexandria, Egypt," Research Journal of Microbiology, vol. 6, no. 10, pp. 750-760, 2011.

[28] A. Poulou, E. Voulgari, G. Vrioni et al., "Imported Klebsiella pneumoniae carbapenemase-producing $K$. pneumoniae clones in a Greek hospital: Impact of infection control measures for restraining their dissemination," Journal of Clinical Microbiology, vol. 50, no. 8, pp. 2618-2623, 2012.

[29] S. M. Al Johani, J. Akhter, H. Balkhy, A. El-Saed, M. Younan, and Z. Memish, "Prevalence of antimicrobial resistance among gram-negative isolates in an adult intensive care unit at a tertiary care center in Saudi Arabia," Annals of Saudi Medicine, vol. 30, no. 5, pp. 364-369, 2010.

[30] I. Galani, P. D. Rekatsina, D. Hatzaki, D. Plachouras, M. Souli, and H. Giamarellou, "Evaluation of different laboratory tests for the detection of metallo- $\beta$-lactamase production in Enterobacteriaceae," Journal of Antimicrobial Chemotherapy, vol. 61, no. 3, pp. 548-553, 2008.

[31] F. Shahcheraghi, V. S. Nikbin, and M. M. Feizabadi, "Identification and genetic characterization of metallo-beta-lactamaseproducing strains of Pseudomonas aeruginosa in Tehran, Iran," New Microbiologica, vol. 33, no. 3, pp. 243-248, 2010.

[32] F. Shahcheraghi, M. Abbasalipour, M. M. Feizabadi, G. H. Ebrahimipour, and N. Akbari, "Isolation and genetic characterization of metallo- $\beta$-lactamase and carbapenamase producing strains of Acinetobacter baumannii from patients at tehran hospitals," Iranian Journal of Microbiology, vol. 3, no. 2, pp. 6874, 2011.

[33] A. A. Shah, F. Hasan, S. Ahmed, and A. Hameed, "Characteristics, epidemiology and clinical importance of emerging strains of Gram-negative bacilli producing extended-spectrum $\beta$-lactamases," Research in Microbiology, vol. 155, no. 6, pp. 409421, 2004.

[34] F. Eftekhar, M. Rastegar, M. Golalipoor, and N. Mansoursamaei, "Detection of extended spectrum B-lactamases in urinary isolates of Klebsiella pneumoniae in relation to $B l a_{\mathrm{SHV}}, B l a_{\mathrm{TEM}}$ and Bla vol. 41, no. 3, pp. 127-132, 2012.

[35] D. Ojdana, P. Sacha, P. Wieczorek et al., "The occurrence of $b l a_{\mathrm{CTX}-\mathrm{M}}, b l a_{\mathrm{SHV}}$, and $b l a_{\mathrm{TEM}}$ genes in extended-spectrum $\beta$ lactamase-positive strains of Klebsiella pneumoniae, Escherichia coli, and Proteus mirabilis in Poland," International Journal of Antibiotics, vol. 2014, Article ID 935842, 7 pages, 2014.

[36] G. Cuzon, T. Naas, P. Bogaerts, Y. Glupczynski, and P. Nordmann, "Evaluation of a DNA microarray for the rapid detection of extended-spectrum $\beta$-lactamases (TEM, SHV and CTX-M), plasmid-mediated cephalosporinases (CMY-2-like, DHA, FOX, ACC-1, ACT/MIR and CMY-1-like/MOX) and carbapenemases (KPC, OXA-48, VIM, IMP and NDM)," Journal of Antimicrobial Chemotherapy, vol. 67, no. 8, Article ID dks156, pp. 1865-1869, 2012.

[37] K. Zurfluh, H. Hächler, M. Nüesch-Inderbinen, and R. Stephan, "Characteristics of extended-spectrum $\beta$-lactamase- and carbapenemase-producing Enterobacteriaceae isolates from rivers and lakes in Switzerland," Applied and Environmental Microbiology, vol. 79, no. 9, pp. 3021-3026, 2013.

[38] R. H. Pokhrel, B. Thapa, R. Kafle, P. K. Shah, and C. Tribuddharat, "Co-existence of beta-lactamases in clinical isolates of 
Escherichia coli from Kathmandu, Nepal," BMC Research Notes, vol. 7, article 694, 2014.

[39] H. Alsayed Gaber, M. A. Ahmed, B. M. Rania, M. Mohammed, and M. A. Osama, "Mathematical modeling and classification of viruses from herpesvirus family," International Journal of Computer Applications, vol. 87, no. 12, pp. 5-13, 2014. 

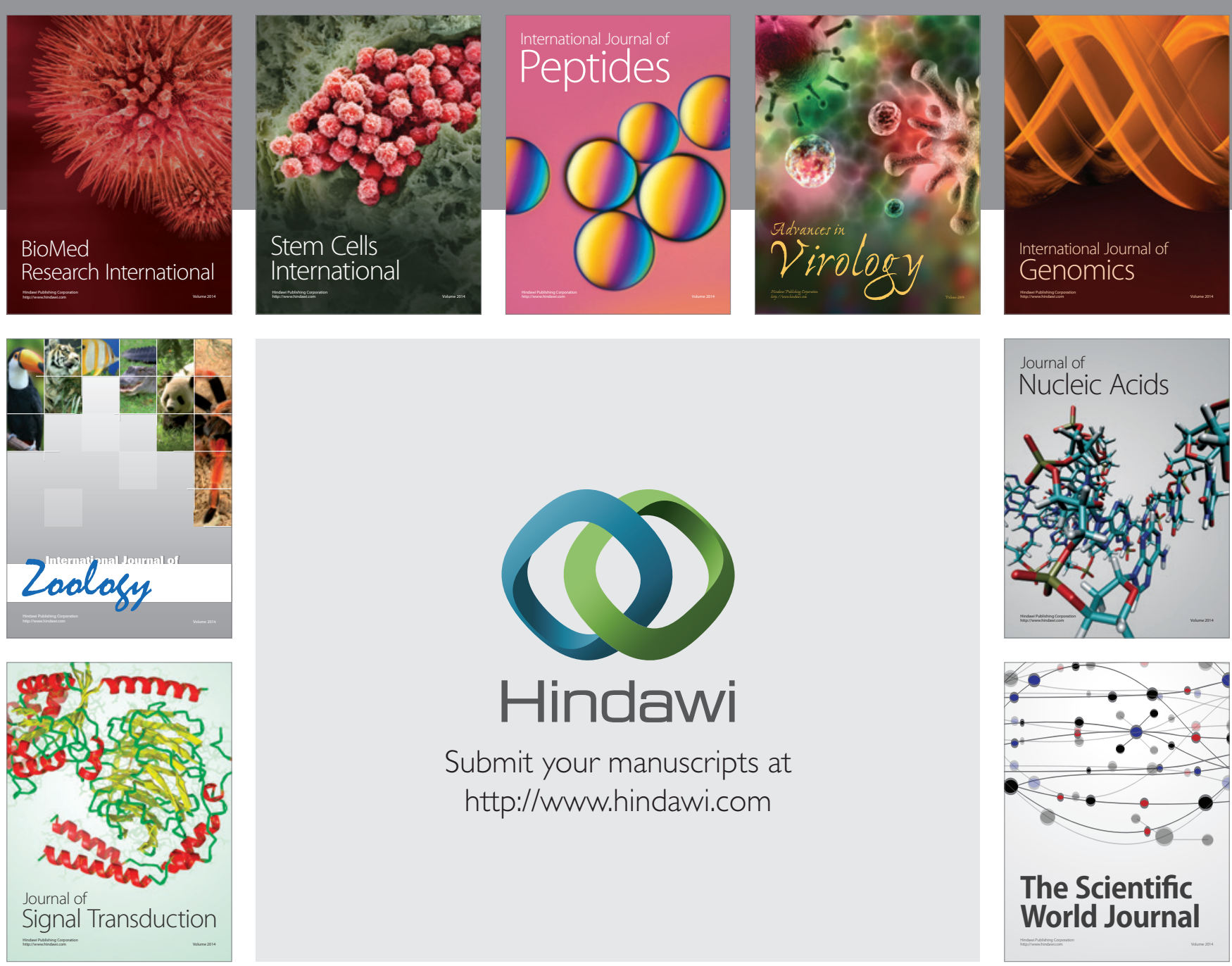

Submit your manuscripts at

http://www.hindawi.com
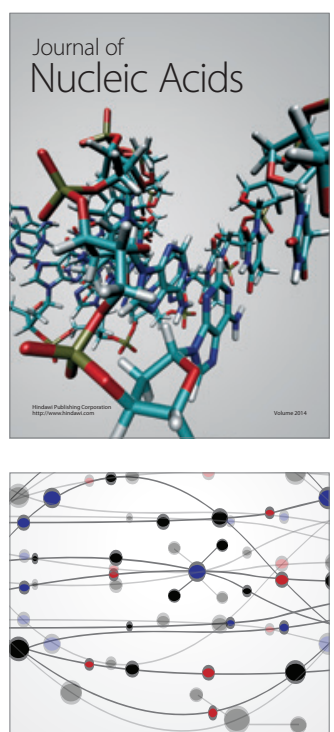

The Scientific World Journal
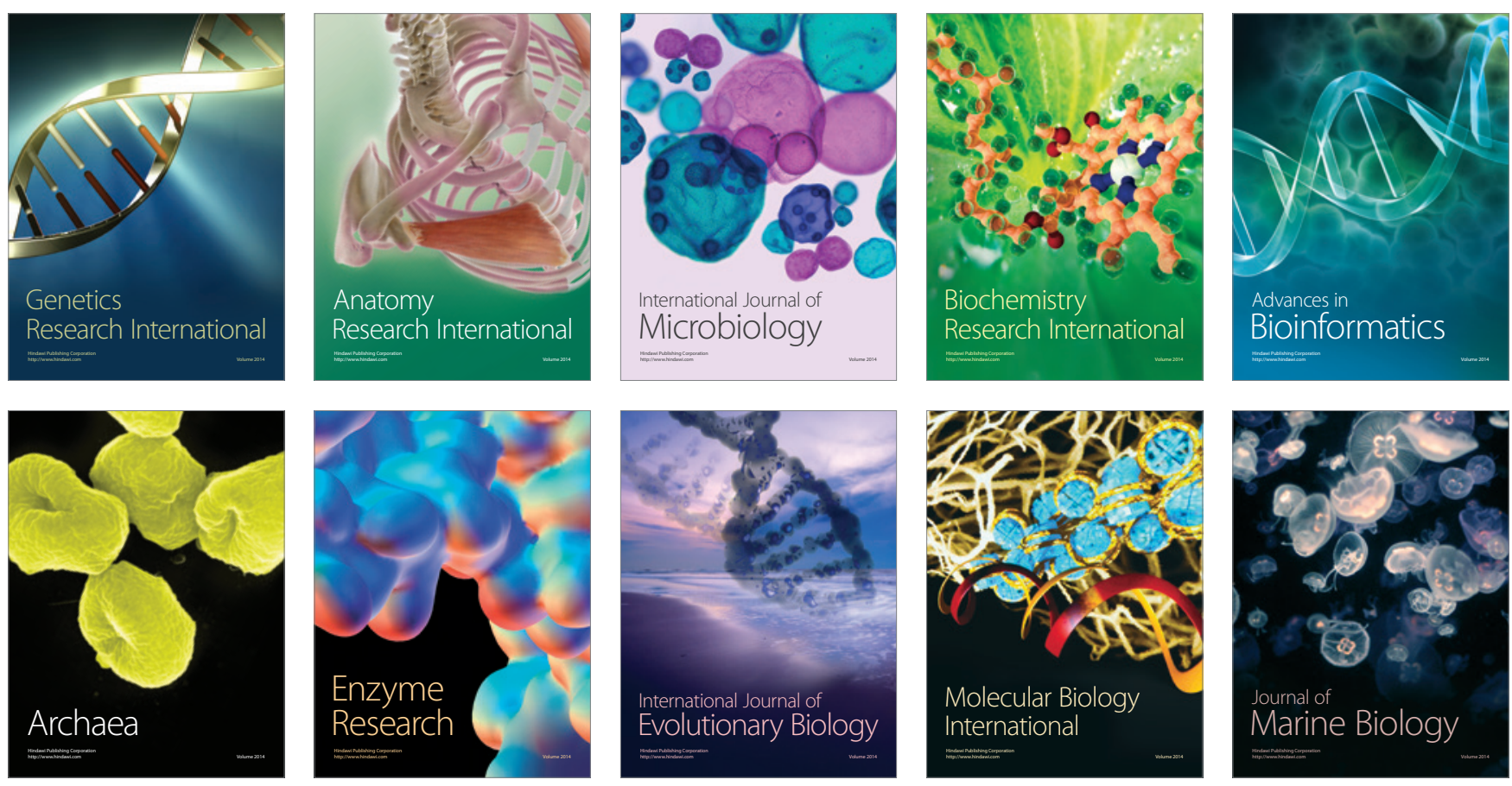